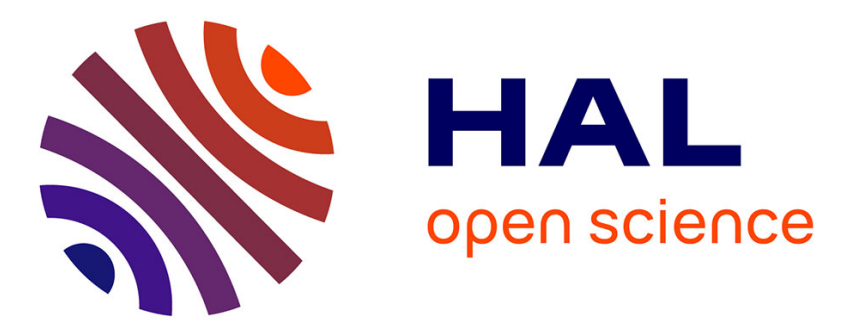

\title{
Are the empirical relationships describing the bio-optical properties of case 1 waters consistent and internally compatible?
}

Andre Morel

\section{- To cite this version:}

Andre Morel. Are the empirical relationships describing the bio-optical properties of case 1 waters consistent and internally compatible?. JOURNAL OF GEOPHYSICAL RESEARCH-OCEANS, 2009, 114, 10.1029/2008JC004803 . hal-03505030

\section{HAL Id: hal-03505030 \\ https://hal.science/hal-03505030}

Submitted on 31 Dec 2021

HAL is a multi-disciplinary open access archive for the deposit and dissemination of scientific research documents, whether they are published or not. The documents may come from teaching and research institutions in France or abroad, or from public or private research centers.
L'archive ouverte pluridisciplinaire HAL, est destinée au dépôt et à la diffusion de documents scientifiques de niveau recherche, publiés ou non, émanant des établissements d'enseignement et de recherche français ou étrangers, des laboratoires publics ou privés.

$$
\text { Copyright }
$$




\title{
Are the empirical relationships describing the bio-optical properties of case 1 waters consistent and internally compatible?
}

\author{
André Morel $^{1}$ \\ Received 7 March 2008; revised 2 October 2008; accepted 3 November 2008; published 30 January 2009. \\ [1] Empirical relationships have been previously established in case 1 waters, by which \\ some inherent optical properties such as particle absorption, scattering and attenuation \\ coefficients, or some apparent properties, such as diffuse attenuation, reflectance, and \\ color band ratios, have been statistically related to the chlorophyll concentration [Chl]. \\ These relationships are at the basis of most of the bio-optical models; with their \\ uncertainties, they describe average trends along the [Chl] range of certain optical \\ properties, around which a natural variability occurs. Through closure exercises and \\ inversions, it is examined whether the presently available, and independently established, \\ empirical relationships form a set of compatible equations. This approach also allows \\ other, less frequently measured properties to be inferred, such as the absorption by \\ dissolved colored matter, $\mathrm{a}_{\mathrm{y}}$, which appears to be larger than often anticipated and to \\ behave on average as a power function of [Chl] in case 1 waters. The spectra of the single \\ scattering albedo of particulate matter are also derived; whatever [Chl], they distinctly \\ exhibit the imprint of the algal pigment absorption. The consistency between the present \\ approach and the GSM inversion scheme (developed by Garver, Siegel, and Maritorena) is \\ also verified. Globally, it is found that within their own uncertainty (resulting from \\ measurements) and variability levels (resulting from natural causes), the main historical \\ relationships describing the bio-optical state of case 1 waters appear to be mutually \\ coherent and compatible.
}

Citation: Morel, A. (2009), Are the empirical relationships describing the bio-optical properties of case 1 waters consistent and internally compatible?, J. Geophys. Res., 114, C01016, doi:10.1029/2008JC004803.

\section{Introduction and Objectives}

[2] Chlorophyll concentration, denoted [Chl], was employed as a convenient index of the "bio-optical state" of oceanic waters when it was realized that the changes in the optical properties of these waters are rather regularly organized with respect to it (Smith and Baker [1978], also historical review by Mobley et al. [2004]). The adoption of this index was also guided by methodological considerations because this pigment was routinely measured at sea. Thus [Chl] became a useful descriptor of phytoplanktonic biomass, and, by extension, a global indicator of the trophic state and abundance of various materials deriving from algal cells. These cells, and accompanying biogenous materials, form the optically influential components which determine the bulk optical properties of case 1 waters.

[3] At least as a heuristic approach, the choice of [Chl] as a global index for case 1 optical properties was not groundless. Indeed, far from terrestrial runoff and terrigeneous influence, oceanic water essentially contain products

\footnotetext{
${ }^{1}$ Laboratoire d'Océanographie de Villefranche, Université Pierre et Marie Curie et Centre National de la Recherche Scientifique, Villefranchesur-mer, France.

Copyright 2009 by the American Geophysical Union. 0148-0227/09/2008JC004803
}

(and by-products) of the initial photosynthetic process, by which particulates were created as chlorophyll-bearing algal cells. Thereafter, the decay of these cells and the activity of grazers, create a retinue of dissolved, colloidal and particulate detrital matter, to which heterotrophic organisms (bacteria and viruses) are added.

[4] The bio-optical properties of case 1 waters have been progressively extracted via statistical studies by which several optical properties and coefficients have been empirically related solely to [Chl], even if they depend on the ensemble of biological material. From the early beginning, it has been repeatedly stressed that such relationships, with their own uncertainties, are "average laws" for case 1 waters; as such they are only able to describe the mean trends of certain optical properties over a wide [Chl] range, but not specific traits at regional scale or within a narrow [Chl] range. In the work by Gordon and Morel [1983, page 65-67] "natural causes of deviation with respect to average laws" were clearly identified. For a given [Chl], variability in the bio-optical properties is to be expected because of possible fluctuations (1) in the pigment composition and packaging effect inside the phytoplankton community and species assemblages; (2) between the respective proportions of algal and nonalgal particles; and (3) between the relative proportions of particulate matter (algal plus nonalgal) and dissolved colored matter. These fluctuations essentially originate from the lack of phasing in the generation, 
maintenance, and life span of these biogenous materials submitted to various chemical and physical actions (e.g., short-living algal cells versus resistant particulate debris or versus sun-sensitive chromophoric dissolved matter). As a result, the instantaneous [Chl] cannot accurately represent a global biological activity which extends over past periods of varying length.

[5] Somewhat surprisingly, compatibility among the average relationships between optical properties and [Chl] has been a priori assumed without having been specifically verified. Up to now only indirect tests have been realized. Indeed, some of these relationships (mainly those dealing with diffuse attenuation and scattering) have been successfully combined into general [Chl]-dependent bio-optical models for case 1 waters [e.g., Morel and Gentili, 2004], and these models allowed the development of efficient semianalytical algorithms for ocean color interpretation [e.g., Gordon et al., 1988; Morel, 1988; Morel et al., 2007c], and supported empirical algorithms in use for the retrieval of [Chl] from space [O'Reilly et al., 1998]. They also set the framework for a model-based on-orbit vicarious calibration approach applicable to ocean color sensors [Werdell et al., 2007]. Notwithstanding the considerable achievements of such indirect tests, direct verifications of an internal coherency among the empirical relationships remain to be made.

[6] The main goal of the present study is to investigate whether the current average laws are mutually consistent, and specifically, whether the spectral inherent and apparent optical properties (IOP and AOP, sensu Preisendorfer [1961]), that were independently related to [Chl] through statistical relationships, form a compatible and coherent set of equations. If the answer is positive, "standards" for average case 1 waters could be drawn.

\section{Available Empirical Relationships and Methodological Aspects}

[7] Among the well documented relationships between IOPs and [Chl] (see Appendix for coefficients, uncertainties, and statistics), one deals with the spectral absorption by all particles, $a_{p}(\lambda)$, [Bricaud et al., 1998], another one with absorption by phytoplankton only, $\mathrm{a}_{\varphi}(\lambda)$ [Bricaud et al., 1995], and a third one, involves the particle scattering coefficient, $\mathrm{b}_{\mathrm{p}}$ ([Gordon and Morel [1983], revisited by Loisel and Morel [1998]). Voss [1992] examined the particle beam attenuation coefficient, $\mathrm{c}_{\mathrm{p}}(\lambda)$, with $\mathrm{c}_{\mathrm{p}}(\lambda)=\mathrm{a}_{\mathrm{p}}(\lambda)+$ $\mathrm{b}_{\mathrm{p}}(\lambda)$, and its dependence with respect to [Chl]. Between AOPs and [Chl], other empirical relationships are also available; the diffuse attenuation coefficient for downward irradiance, $\mathrm{K}_{\mathrm{d}}(\lambda)$, was studied as a function of [Chl] [Baker and Smith, 1982; Gordon et al., 1988; Morel, 1988; Morel and Maritorena, 2001]; the reflectance spectra, $\mathrm{R}(\lambda)$, were also empirically related to [Chl] [e.g., O’Reilly et al., 2000].

[8] The measurements leading to the above optical parameters are quite differing. Water samples are collected for the determination of $a_{p}(\lambda)$, and this coefficient is then measured in vitro via spectrophotometry of the particles retained by filtration on glass-fiber filters; the coefficient $\mathrm{a}_{\varphi}$ $(\lambda)$ is determined on the same samples after some chemical [Kishino et al., 1985] or numerical [Bricaud and Stramski, 1990] manipulations. In contrast, the $c_{p}(\lambda), a_{p}(\lambda)$, and $b_{p}(\lambda)$ coefficients are measured in situ by operating profiling instruments (a-c, or b-meters). The $\mathrm{K}_{\mathrm{d}}(\lambda)$ coefficients also derive from in situ radiometric measurements of downward spectral irradiance, $\mathrm{E}_{\mathrm{d}}(\lambda)$, while the upward irradiance $\mathrm{E}_{\mathrm{u}}(\lambda)$ is combined with $\mathrm{E}_{\mathrm{d}}(\lambda)$ at the same depth to produce the irradiance reflectance, $\mathrm{R}(\lambda)=\mathrm{E}_{\mathrm{u}}(\lambda) / \mathrm{E}_{\mathrm{d}}(\lambda)$. Several ways of testing the compatibility between these various independent relationships are examined below.

\subsection{Absorption and Diffuse Attenuation Coefficients}

[9] The spectral coefficients of particle absorption and of phytoplankton absorption, $\mathrm{a}_{\mathrm{p}}(\lambda)$ and $\mathrm{a}_{\varphi}(\lambda)$, respectively, (units $\mathrm{m}^{-1}$ ) were empirically related to [Chl] (units $\mathrm{mg}$ $\mathrm{m}^{-3}$ ) according to similar power laws [Bricaud et al., 1995; Bricaud et al., 1998], namely

$$
\begin{aligned}
& \mathrm{a}_{\mathrm{p}}(\lambda,[\mathrm{Chl}])=\mathrm{A}_{\mathrm{p}}(\lambda)[\mathrm{Chl}]^{\mathrm{B}_{\mathrm{p}}(\lambda)} \\
& \mathrm{a}_{\varphi}(\lambda,[\mathrm{Chl}])=\mathrm{A}_{\varphi}(\lambda)[\mathrm{Chl}]^{\mathrm{B}_{\varphi}(\lambda)}
\end{aligned}
$$

The (spectral) attenuation coefficient for downward irradiance, $\mathrm{K}_{\mathrm{d}}(\lambda)$ (units $\mathrm{m}^{-1}$ ), was related to [Chl] according to [Morel, 1988; Morel and Maritorena, 2001]

$$
\mathrm{K}_{\mathrm{d}}(\lambda,[\mathrm{Chl}])=\mathrm{K}_{\mathrm{w}}(\lambda)+\chi(\lambda)[\mathrm{Chl}]^{\mathrm{e}(\lambda)}
$$

where $K_{w}(\lambda)$ represents the constant contribution of pure water. The diffuse attenuation coefficient, $K_{d}$, is chiefly governed by the absorption coefficient, a, [Gordon, 1989a], where $\mathrm{a}\left(=\mathrm{a}_{\mathrm{w}}+\mathrm{a}_{\mathrm{p}}+\mathrm{a}_{\mathrm{y}}\right)$ is the sum of the absorption coefficients of water, particles, and dissolved colored matter (yellow substance), respectively. Some links, or at least, a certain compatibility must exist along the [Chl] range and for the same wavelength between the two relationships, $\mathrm{K}_{\mathrm{d}}(\lambda) \leftrightarrow[\mathrm{Chl}]$, and $\mathrm{a}_{\mathrm{p}}(\lambda) \leftrightarrow[\mathrm{Chl}]$.

[10] The coefficients $A_{p}(\lambda), A_{\varphi}(\lambda)$, and $\chi(\lambda)$ determine the magnitude and spectral shape of $a_{p}, a_{\varphi}$, and $K_{d}$ when $[\mathrm{Chl}]=1 \mathrm{mg} \mathrm{m}^{-3}$. The exponents, $\mathrm{B}_{\mathrm{p}}(\lambda), \mathrm{B}_{\varphi}(\lambda)$ and $\mathrm{e}(\lambda)$ determine the dependence on [Chl]. They are all notably below one $(\sim 0.7)$, which means that the increases in the optical coefficients, $\mathrm{a}_{\mathrm{p}}, \mathrm{a}_{\varphi}$, and $\mathrm{K}_{\mathrm{d}}$, are less steep than the [Chl] increase itself.

[11] The compatibility between the empirical relationships providing $\mathrm{a}_{\mathrm{p}}$ and $\mathrm{K}_{\mathrm{d}}$ can be studied as follows. First, $\mathrm{K}_{\mathrm{d}}(\lambda,[\mathrm{Chl}])$, from equation (2), can be inverted [Morel et al., 2006] to retrieve the total absorption coefficient, denoted $\mathrm{a}_{\mathrm{tot}}$, according to

$$
\begin{aligned}
\mathrm{a}_{\mathrm{tot}}(\lambda,[\mathrm{Chl}])= & 0.97 \mathrm{~K}_{\mathrm{d}}\left(\lambda,[\mathrm{Chl}], \theta_{\mathrm{s}}\right) \mu_{\mathrm{d}}\left(\lambda,[\mathrm{Chl}], \theta_{\mathrm{s}}\right) \\
& \cdot\left\{1-\mathrm{R}\left(\lambda,[\mathrm{Chl}], \theta_{\mathrm{s}}\right) / \mathrm{f}^{\prime}\left(\lambda,[\mathrm{Chl}], \theta_{\mathrm{s}}\right)\right\}
\end{aligned}
$$

The dependence of $\mathrm{K}_{\mathrm{d}}$ on the sun zenith angle, $\theta_{\mathrm{s}}$ (for clear skies), which was ignored in equation (2), is made explicit in equation (3). The average cosine for downward irradiance, $\mu_{\mathrm{d}}$, as well as the irradiance reflectance, $\mathrm{R}$, and the dimensionless coefficient $\mathrm{f}^{\prime}$, depend on the same arguments, namely, on $\lambda, \theta_{\mathrm{s}}$. and [Chl]. The coefficient $\mathrm{f}^{\prime}$ [Gordon, 1989b] relates $\mathrm{R}$ to the inherent optical properties, 
$\mathrm{a}$ and $\mathrm{b}_{\mathrm{b}}$, the absorption and backscattering coefficients, respectively, through (arguments omitted)

$$
\mathrm{R}=\mathrm{f}^{\prime}\left[\mathrm{b}_{\mathrm{b}} /\left(\mathrm{a}+\mathrm{b}_{\mathrm{b}}\right)\right]
$$

The dimensionless quantities $\mu_{\mathrm{d}}, \mathrm{R}$, and $\mathrm{f}^{\prime}$ have been modeled for case 1 waters as a function of the three quantities $\lambda,[\mathrm{Chl}]$, and $\theta_{\mathrm{s}}$ [Morel et al., 2002; Morel and Gentili, 2004]. Using equation (3) to retrieve $\mathrm{a}_{\text {tot }}$ poses a problem because $\theta_{\mathrm{s}}$ is not specified. Indeed, the $\mathrm{K}_{\mathrm{d}}$ field values were merged regardless of the sun position for the statistical analysis leading to equation (2). Actually, these $\mathrm{K}_{\mathrm{d}}$ values have been determined mostly in temperate or subtropical zones, and generally around the local solar noon; therefore, a constant $\theta_{\mathrm{s}}$ value $\left(=30^{\circ}\right)$ is adopted as representative on average of the experimental conditions (arguments for this choice are presented by Morel and Gentili [2004]). Under this assumption, the inversion via equation (3) can be performed to obtain the $\mathrm{a}_{\mathrm{tot}}(\lambda,[\mathrm{Chl}])$ coefficients over the entire [Chl] range. In a second step, the particle absorption (equation (1)) and the pure water absorption, $\mathrm{a}_{\mathrm{w}}$, are both subtracted from $\mathrm{a}_{\mathrm{tot}}$, so that the absorption by the dissolved yellow-colored matter, denoted $\mathrm{a}_{\mathrm{y}}$, is derived as

$$
\mathrm{a}_{\mathrm{y}}(\lambda,[\text { Chl }])=\mathrm{a}_{\mathrm{tot}}(\lambda,[\text { Chl }])-\mathrm{a}_{\mathrm{p}}(\lambda,[\text { Chl }])-\mathrm{a}_{\mathrm{w}}(\lambda)
$$

\subsection{Attenuation, Absorption, and Scattering Coefficients}

[12] The particle attenuation coefficient, $\mathrm{c}_{\mathrm{p}}$, (units $\mathrm{m}^{-1}$ ) is the sum of the particle absorption and particle scattering coefficients, $a_{p}$ and $b_{p}$, respectively

$$
\mathrm{c}_{\mathrm{p}}(\lambda)=\mathrm{a}_{\mathrm{p}}(\lambda)+\mathrm{b}_{\mathrm{p}}(\lambda)
$$

$\mathrm{a}_{\mathrm{p}}(\lambda)$ depends on the pigmentation within the particles, whereas $b_{p}(\lambda)$ depends essentially on the refractive index and the size distribution function of these particles. These coefficients are physically distinct except that they both reflect the particle abundance, itself depicted by the [Chl] index. Reassembling these properties as observed in the field in order to examine their agreement with $c_{p}(\lambda)$ is worth being explored. For such a test, the following independent empirical relationships are available; beside $a_{p}(\lambda,[C h l])$, already expressed through equation (1), the relationship between $b_{p}$ and [Chl] in case 1 waters was also found to be of the generic form [Gordon and Morel, 1983]

$$
\mathrm{b}_{\mathrm{p}}(\lambda,[\mathrm{Chl}])=\mathrm{B}_{0}(\lambda)[\mathrm{Chl}]^{\beta}
$$

On the basis of in situ measurements, an empirical relationship was proposed by Voss [1992]

$$
\mathrm{c}_{\mathrm{p}}(\lambda,[\mathrm{Chl}])=\mathrm{C}_{0}(\lambda)[\mathrm{Chl}]^{\Gamma}
$$

Equations (1), (7), and (8) are thus available for a numerical closure as specified by equation (6). It is worth noting that the exponents $\beta$ and $\Gamma$ in equations (7) and (8), like those in equations (1) and (2), are consistently below one.
[13] When attempting the closure, it must be kept in mind that the absorption and scattering contributions in forming $\mathrm{c}_{\mathrm{p}}$ are strongly unbalanced. In the green part of the spectrum, around $560 \mathrm{~nm}$, and even in the red part of the spectrum where algal absorption increases (near $660 \mathrm{~nm}$ ), $a_{p}$ is almost negligible compared to $b_{p}$, so that $c_{p}$ is often considered as a surrogate for $b_{p}$ at these wavelengths [e.g., Boss et al., 2001]. A closer examination of the relative magnitude of $a_{p}$ and $b_{p}$ is more perceptively obtained by forming the ratio $\varpi_{p}$

$$
\varpi_{\mathrm{p}}=\mathrm{a}_{\mathrm{p}} /\left(\mathrm{a}_{\mathrm{p}}+\mathrm{b}_{\mathrm{p}}\right)
$$

which is the single scattering albedo for marine particles. Its magnitude and spectral behavior, $\varpi_{p}(\lambda)$, for which some documentation and theoretical consideration do exist, is a sensitive tool when assessing the compatibility between the empirical relationships by which $a_{p}(\lambda)$ and $b_{p}(\lambda)$ were independently expressed.

\subsection{Spectral Reflectance: Empirical and Semianalytical Approaches}

[14] The variations in the ratio $\mathrm{R}_{\mathrm{j}}^{\mathrm{i}}=\mathrm{R}\left(\lambda_{\mathrm{i}}\right) / \mathrm{R}\left(\lambda_{\mathrm{j}}\right)$ of two reflectances at two wavelengths, $\lambda_{\mathrm{i}}$ and $\lambda_{\mathrm{j}}$, have been directly related to [Chl] through statistical relationships [Clark, 1981; O'Reilly et al., 1998; O'Reilly et al., 2000]. Actually, the same ratios can be produced via semianalytical models [e.g., Gordon et al., 1988; Morel and Maritorena, 2001]. Such models are built by using the above mentioned relationships, between $\mathrm{K}_{\mathrm{d}}, \mathrm{a}_{\mathrm{p}}$, and $\mathrm{b}_{\mathrm{p}}$ and [Chl]. Therefore, comparing the (direct) empirical relationships obtained by O'Reilly et al.[2000] with the results of (indirect) semianalytical approaches amounts to examining the compatibility between the various and independent empirical relationships involved in both methods.

[15] The purely empirical approach results in algorithms which were obtained as being the best fit when the log transform of the observed [Chl] values were related to the $\log$ transform of band ratios, $\mathrm{R}_{\mathrm{j}}^{\mathrm{i}}$, (i.e., the ratios of remote sensing reflectance measured in the field at two wavelengths, $i$ and $j$ ). As the best fit is achieved by using polynomials (of the 4th order, in general), the resulting empirical expressions are of the type

$$
\log _{10}[\mathrm{Chl}]=\mathrm{a}_{0}+\sum_{1}^{N} \mathrm{a}_{n}\left(\log _{10} \mathrm{R}_{j}^{i}\right)^{n}
$$

[16] Semianalytical hyperspectral approaches [Gordon et al., 1988; Morel, 1988] consist of expressing both the absorption coefficient, $\mathrm{a}(\lambda)$, and the backscattering coefficient, $b_{b}(\lambda)$, and then operating equation (4). In a recent version [Morel and Maritorena, 2001] (hereinafter denoted MM01), equations (2) and (3) are used to obtain the absorption coefficient. The backscattering coefficient, $\mathrm{b}_{\mathrm{b}}=$ $\left(b_{b w}+b_{b p}\right)$, is the sum of the water molecule and particle backscattering coefficients. The coefficient $b_{b p}$ is obtained as the product of the backscattering probability, $\tilde{b}_{\mathrm{bp}}$ and the particle scattering coefficient, $b_{p}$. (equations (13) and (12), respectively, in MM01). The $b_{p}(\lambda,[\mathrm{Chl}])$ values needed at other wavelengths are obtained by using equations $(18-19)$ (see later). Through this modeling approach, the spectral 

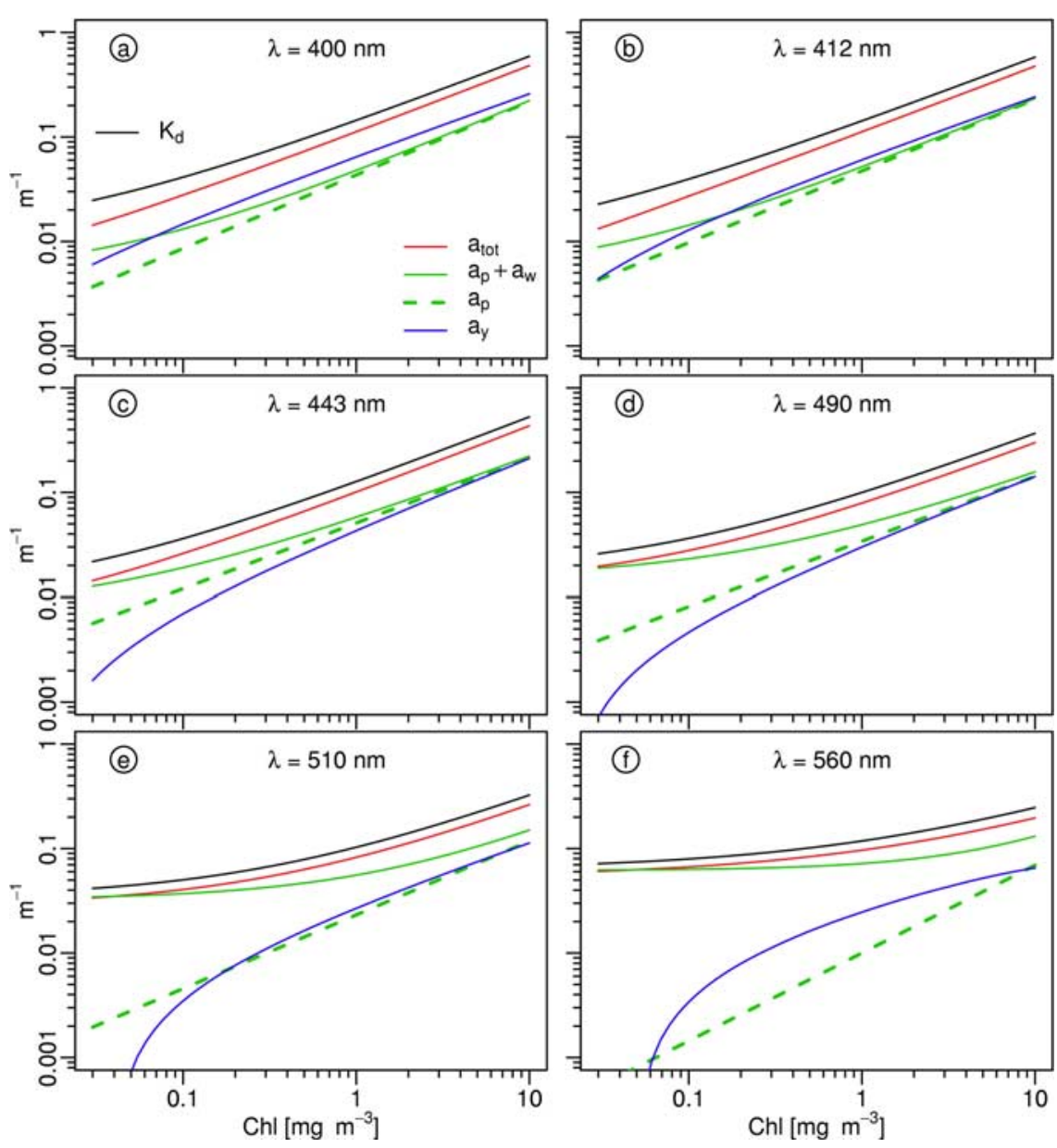

Figure 1. Figures 1a-1f correspond to selected wavelengths as indicated. Each of them display the variations along the [Chl] range $\left(\mathrm{mg} \mathrm{m}^{-3}\right)$ of several optical coefficients $\left(\mathrm{m}^{-1}\right)$, namely, the particle absorption coefficient, $a_{p}$ (equation (1)), the diffuse attenuation coefficient, $K_{d}$ (equation (2)), the total absorption coefficient, $a_{\text {tot }}$ (derived from $\mathrm{K}_{\mathrm{d}}$, via equation (3)), the sum $\left(\mathrm{a}_{\mathrm{p}}+\mathrm{a}_{\mathrm{w}}\right)$ (where $\mathrm{a}_{\mathrm{w}}$ is the absorption coefficient by pure water), and the yellow substance absorption, $\mathrm{a}_{\mathrm{y}}$ (obtained through equation (5)). Both scales are logarithmic.

reflectances, $\mathrm{R}(\lambda)$, as well as any $\mathrm{R}_{\mathrm{j}}^{\mathrm{i}}$ ratio, can be related to [Chl].

[17] The compatibility between the independent relationships involved in both the empirical and semianalytical approaches can be tested, and the tests will be successful if the $\mathrm{R}_{\mathrm{j}}^{\mathrm{i}} \leftrightarrow[\mathrm{Chl}]$ empirical dependencies (expressed by equation (10)) do agree with those predicted by the MM01 model, based on equation (4). The Garver, Siegel, and Maritorena (GSM) bio-optical multispectral model, introduced by Garver and Siegel [1997] later updated by Maritorena et al. [2002], is also a semianalytical model which makes use of equation (4) (actually a similar form) and several assumptions. Another test is thus possible and will be presented.

\section{Results}

\subsection{Absorption Coefficient and Components of Absorption}

[18] Results are presented according to the scheme outlined in section 2. The $\chi(\lambda)$ and $\mathrm{e}(\lambda)$ values (cf. Appendix) are used to obtain the $\mathrm{K}_{\mathrm{d}}(\lambda,[\mathrm{Chl}]$ ) values (via equation (2), increment $5 \mathrm{~nm})$, which are then transformed into $\mathrm{a}_{\mathrm{tot}}(\lambda$, [Chl]) by operating equation (3), with $\theta_{\mathrm{s}}=30^{\circ}$, and using the $\mathrm{R}\left(\lambda,[\mathrm{Chl}], \theta_{\mathrm{s}}\right)$ and $\mathrm{f}^{\prime}\left(\lambda,[\mathrm{Chl}], \theta_{\mathrm{s}}\right)$ values provided by the MM01 model. These total absorption values are then compared to the sum $a_{p}(\lambda,[C h l])+a_{w}(\lambda)$, where the $a_{p}(\lambda$, [Chl]) values are computed with the parameters given by Bricaud et al. [1998], and the $\mathrm{a}_{\mathrm{w}}(\lambda)$ coefficients are adopted from Pope and Fry [1997] (except $\mathrm{a}_{\mathrm{w}}(400)$ which is taken equal to $0.0046 \mathrm{~m}^{-1}$, from Morel et al. [2007b]). Such comparisons are displayed in Figure 1 for selected wavelengths between 400 and $560 \mathrm{~nm}$, and for the $0.03-$ $10 \mathrm{mg} \mathrm{m}^{-3}$ [Chl] range. The yellow matter absorption, $\mathrm{a}_{\mathrm{y}}(\lambda,[\mathrm{Chl}])$, derived through equation (5), is shown on Figures $1 \mathrm{a}-1 \mathrm{f}$. They deserve several comments.

\subsubsection{Overall Consistency}

[19] There is a manifest consistency between the absorption values, $a_{\text {tot }}(\lambda,[\mathrm{Chl}])$, as provided by the $\mathrm{K}_{\mathrm{d}}$ inversion, and those obtained from the direct regression analysis of $\mathrm{a}_{\mathrm{p}}(\lambda,[\mathrm{Chl}])$, to which the pure water absorption, $\mathrm{a}_{\mathrm{w}}(\lambda)$ has been added. Their concomitant trends extend throughout the whole [Chl] range, and reflect the overall compatibilities between $A_{p}$ and $\chi$, and between $B_{p}$ and e, i.e., between the 


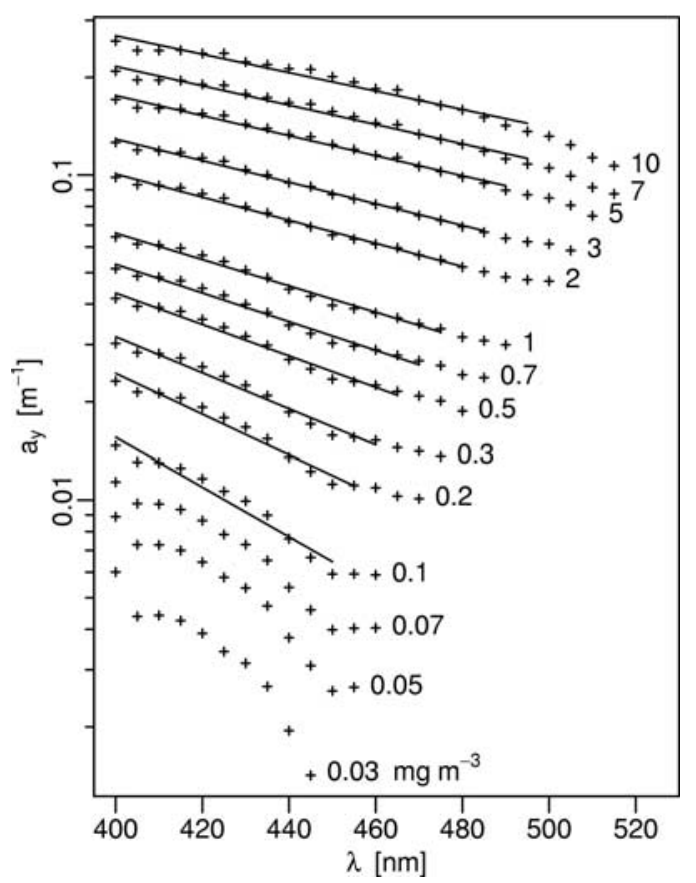

Figure 2. Spectral variations of $\mathrm{a}_{\mathrm{y}}$ (logarithmic ordinates) for various [Chl] values, as indicated. The crosses are the results of systematic calculations similar to those displayed in Figure 1 but at all wavelengths (5 $\mathrm{nm}$ increment). The solid lines correspond to the best fits to an exponential decrease (equation (12)), computed between $\lambda=400 \mathrm{~nm}$ and a varying upper limit (see text). The $\mathrm{r}^{2}$ values for these fits vary from 0.928 when $[\mathrm{Chl}]=0.1 \mathrm{mg} \mathrm{m}^{-3}$ and increase up to 0.98 for intermediate and high [Chl] values.

two distinct measurements and statistical analyses having led to equations (1) and (2). This internal consistency also implies that $\mathrm{a}_{\text {tot }}$ must exceed (equation (5)) the sum $\left(\mathrm{a}_{\mathrm{p}}+\right.$ $\left.a_{w}\right)$ to account for the presence of yellow substance, $\left(a_{y}\right)$. This is generally the case, except in the domains of very low [Chl] and large wavelengths; this impossibility in deriving $\mathrm{a}_{\mathrm{y}}$ will be discussed below. If the variability in $\mathrm{a}_{\text {tot }}$ (actually in $\mathrm{K}_{\mathrm{d}}$ ) and in $\mathrm{a}_{\mathrm{p}}$ for a given [Chl] value (see RMSE in Appendix) are considered as independent (when using equation (5)), then the potential variability in $\mathrm{a}_{\mathrm{y}}$ (and as well its uncertainty) are within a factor of about 3 or 4 , according to the wavelength.

\subsubsection{Yellow Substance Absorption Magnitude: Uncertainties in the Oligotrophic Domain}

[20] The yellow substance absorption, $\mathrm{a}_{\mathrm{y}}$, decreases with decreasing [Chl] in a monotonous manner over the upper part of the [Chl] range (Figure 1). It also appears to be an important contributor to the total absorption in the short wavelength domain; at $400-412 \mathrm{~nm}$ for instance, $\mathrm{a}_{\mathrm{y}}$ largely exceeds $a_{p} ; a_{y}$ becomes $<a_{p}$, when $a_{p}$ experiences its maximum at $442 \mathrm{~nm}$, and again it exceeds $a_{p}$ at $510 \mathrm{~nm}$ (for moderate and high [Chl]), when the particle absorption decreases. Beyond $510 \mathrm{~nm}, \mathrm{a}_{\mathrm{w}}$ becomes predominant compared to $a_{p}$ (e.g., $a_{w}=0.062 \mathrm{~m}^{-1}$ at $560 \mathrm{~nm}$ ), so that the two terms, $a_{\text {tot }}$ and $\left(a_{\mathrm{p}}+a_{\mathrm{w}}\right)$, become hardly distinguishable, and their difference, $a_{y}$, is numerically insignificant (or even aberrant, i.e., negative).
[21] When [Chl] is $<0.1 \mathrm{mg} \mathrm{m}^{-3}$, the sum $\left(\mathrm{a}_{\mathrm{p}}+\mathrm{a}_{\mathrm{w}}\right)$ progressively gets very close to $\mathrm{a}_{\text {tot }}$ for most of the wavelengths; thus the assessment of $\mathrm{a}_{\mathrm{y}}$ becomes questionable, except for the shortest wavelengths. The marked convexity (in log-log space, Figure 1) which affects the $\mathrm{a}_{\mathrm{y}}$ curves in the low [Chl] domain reflects this uncertainty and strongly suggests an artifact, attributable either to some numerical limitations in the inversion, or more likely, to a slight incompatibility between the empirical relationships (namely between equations (1) and (2)). It is worth recalling that in the region of the minimal particle absorption (530$630 \mathrm{~nm}$ ), equation (1) becomes more uncertain (decreasing correlation coefficient, $\beta$-correction issue for low optical density; see discussions by Bricaud et al. [1995, 1998]). For other reasons (explained by Morel and Maritorena [2001]), the reliability of equation (2) in the domain of green to red radiation also degrades. The discarded data in Figure 2 (when $\lambda$ increases) correspond to these zones of convexity which appear at low [Chl], and when $\mathrm{a}_{\mathrm{y}}$ is unreliably low.

[22] The retrieved $\mathrm{a}_{\mathrm{y}}(\lambda,[\mathrm{Chl}])$ spectral values are displayed on the semilogarithmic plot of Figure 2. In spite of irregularities, these spectra approximately exhibit an exponential decrease for increasing $\lambda$, whereas they become very noisy at low [Chl]. According to Figure 1, the increasing trends in $\mathrm{a}_{\mathrm{p}}$ and $\mathrm{a}_{\mathrm{y}}$ for increasing [Chl] are roughly concomitant, at least when $[\mathrm{Chl}]>0.1 \mathrm{mg} \mathrm{m}^{-3}$ (i.e., when the $a_{y}$ values are more reliable). Such a similarity entails that the $a_{y}(\lambda)$ coefficients, like $a_{p}(\lambda)$, must on average behave as power functions of [Chl]. Actually, at $\lambda=400 \mathrm{~nm}, \mathrm{a}_{\mathrm{y}}$ verifies such a power function (Figure 3 ), according to

$$
\mathrm{a}_{\mathrm{y}}(400,[\mathrm{Chl}])=0.065[\mathrm{Chl}]^{0.63}
$$

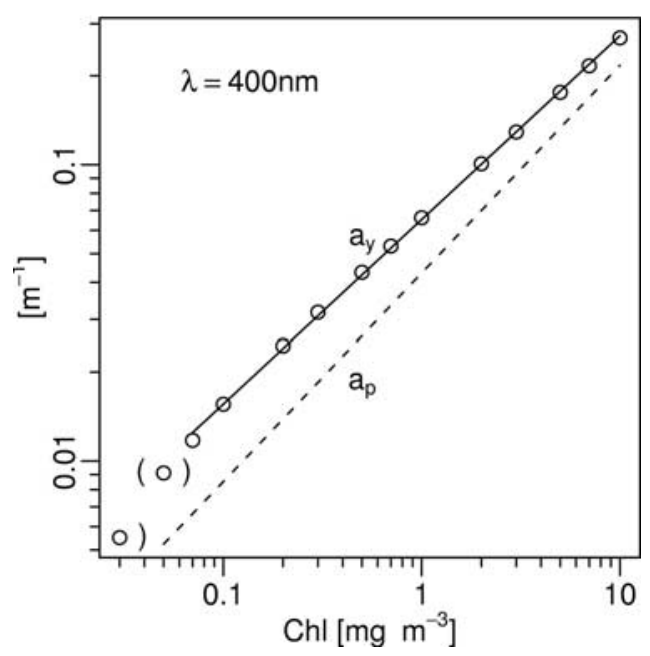

Figure 3. $\mathrm{a}_{\mathrm{y}}(400)$ values (circles) taken from Figure 2 and plotted as a function of [Chl]; the solid line represents the best fit (equation (11), $\mathrm{r} 2=0.9995$, $\mathrm{RMSE}=0.0348$, on the $\log$ transform quantities) if the $\mathrm{a}_{\mathrm{y}}$ values (obtained when [Chl] is $<0.07 \mathrm{mg} \mathrm{m}^{-3}$ ) are discarded. Also shown for comparison is (dashed straight line) the empirical relationship [Bricaud et al., 1998] established for the particle absorption, namely, $\mathrm{a}_{\mathrm{p}}(400)=0.0441[\mathrm{Chl}]^{0.708}(\mathrm{r} 2=0.875$, RMSE $=0.185$, on the log transform quantities). 

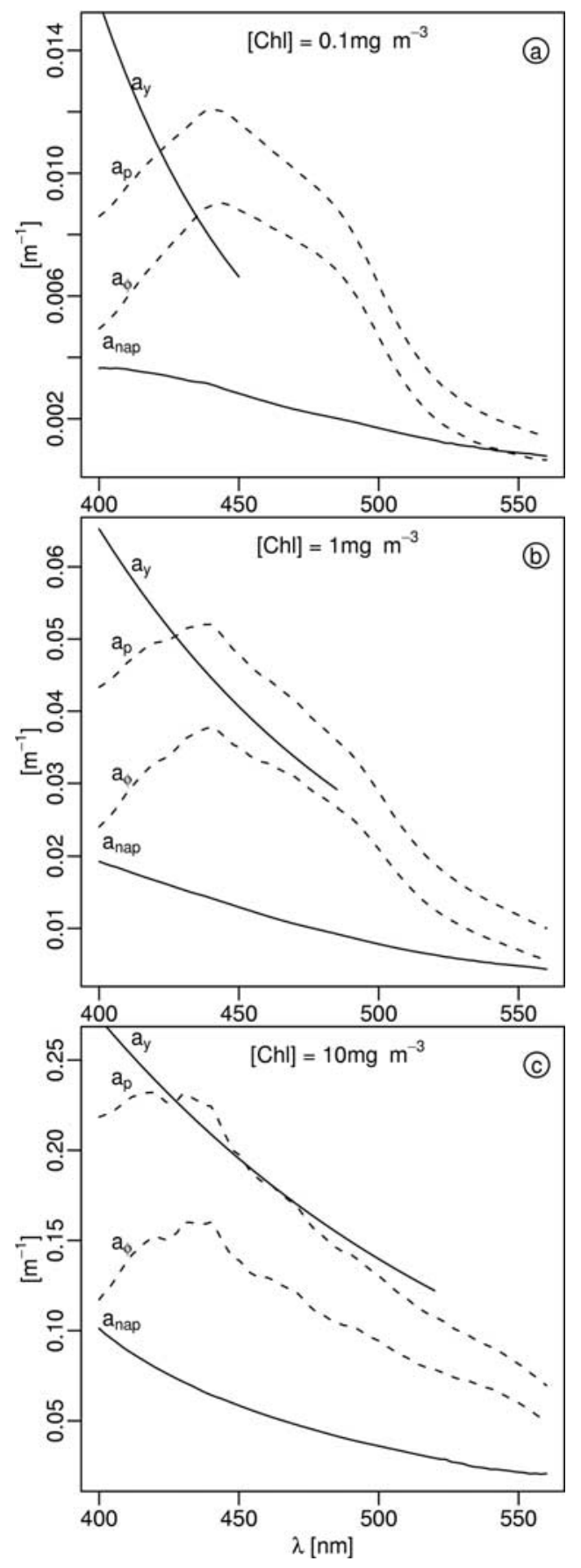

Figure 4. Spectral values of $\mathrm{a}_{\mathrm{p}}, \mathrm{a}_{\varphi}, \mathrm{a}_{\text {nap }}$ (the nonalgal absorption, $a_{\text {nap }}=a_{p}-a_{\varphi}$ ), and $a_{y}$ (the best fit redrawn from Figure 2); these spectra are displayed for three [Chl] values, $0.1,1$, and $10 \mathrm{mg} \mathrm{m}^{-3}$, as indicated (note the changes in the scales of the ordinate axes).

The exponential $\mathrm{a}_{\mathrm{y}}$ decrease (in Figure 2 ) can be characterized by a slope, $\mathrm{S}$, according to

$$
\mathrm{a}_{\mathrm{y}}(\lambda,[\mathrm{Chl}])=\mathrm{a}_{\mathrm{y}}\left(\lambda_{0},[\mathrm{Chl}]\right) \exp \left[-\mathrm{S}\left(\lambda-\lambda_{0}\right)\right]
$$

where $\lambda_{0}$ is set at $400 \mathrm{~nm}$; note that the spectral interval, $\left(\lambda-\lambda_{0}\right)$, within which $\mathrm{a}_{\mathrm{y}}$ can be reliably assessed, dramatically narrows when [Chl] decreases. Apparently
(Figure 2), the descending slope varies with [Chl], namely, $\mathrm{S}$ tends to increase for decreasing [Chl]. Over the (varying) available interval, $\mathrm{S}$ would vary between 0.008 and 0.015 , when [Chl] decreases from 10 to $0.2 \mathrm{mg} \mathrm{m}^{-3}$. Compared to literature values [e.g., Kirk, 1994; Barnard et al., 1998; Bricaud et al., 1981; Twardowski et al., 2004], the S-values at moderate and high [Chl] appear low; rather, they are comparable to the typical values observed for the nonalgal particulate absorption [e.g., Roesler et al., 1989]. Owing to numerical uncertainties already mentioned, or possible incompatibilities, a doubling of the $\mathrm{S}$ value cannot be ascertained, and this point will be reexamined later on (section 4).

\subsubsection{Yellow Substance Absorption Versus Nonalgal Particle Absorption}

[23] It is possible to go farther in this analysis and assess the respective contributions of the various absorbing components, as they result from the average relationships. In addition to $\mathrm{a}_{\mathrm{y}}(\lambda)$, and $\mathrm{a}_{\mathrm{p}}(\lambda)$, are also shown (Figure 4 ) the pure algal absorption, $\mathrm{a}_{\varphi}(\lambda)$ spectra, computed via the empirical equation ( $\left.1^{\prime}\right)$ [from Bricaud et al.,1995]; the nonalgal particle absorption spectra, $\mathrm{a}_{\text {nap }}(\lambda)$, (obtained as the difference between equations (1) and $\left.\left(1^{\prime}\right)\right)$ is also displayed with its typical descending slope toward larger wavelength.

[24] Within the whole "detrital" compartment, the absorption by the dissolved fraction $\left(\mathrm{a}_{\mathrm{y}}\right)$ largely dominates that of the nonalgal particulate fraction $\left(a_{\text {nap }}\right)$, by a factor of $\sim 2-3$ in the blue-green domain, as already noted by Siegel et al. [2002]. As the packaging effect generally increases for increasing [Chl] [Bricaud et al., 2004], the broad $\mathrm{a}_{\mathrm{p}}$ maximum around $442 \mathrm{~nm}$ flattens, and correlatively, the relative role of $\mathrm{a}_{\mathrm{y}}$ at this wavelength is enhanced. For other wavelengths, the respective contributions of dissolved and particulate matters to the total absorption are spectrally varying because $a_{y}(\lambda)$ and $a_{p}(\lambda)$ differ in spectral shapes, and also because their relative proportions vary with [Chl]. This is illustrated by Figure 5.

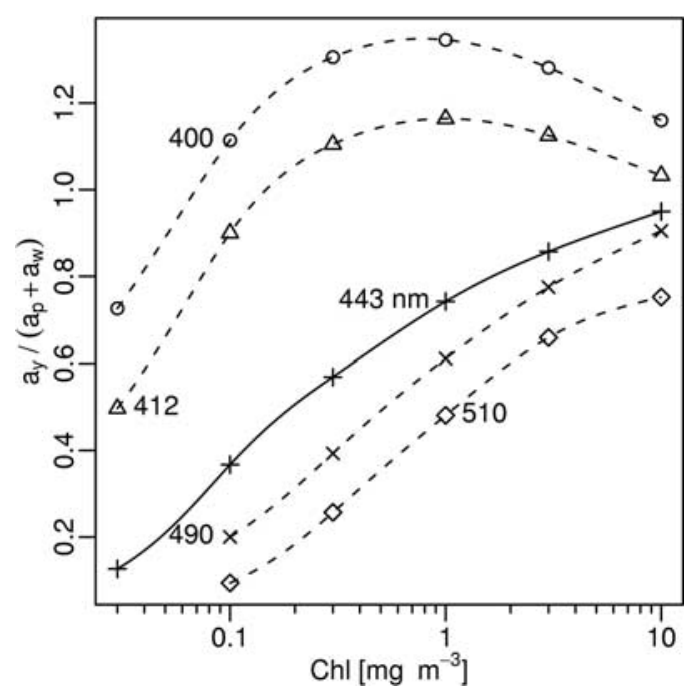

Figure 5. For five selected wavelengths as indicated, variations of the ratio $\mathrm{a}_{\mathrm{y}} /\left(\mathrm{a}_{\mathrm{p}}+\mathrm{a}_{\mathrm{w}}\right)$ along the $[\mathrm{Chl}]$ range (see text). 


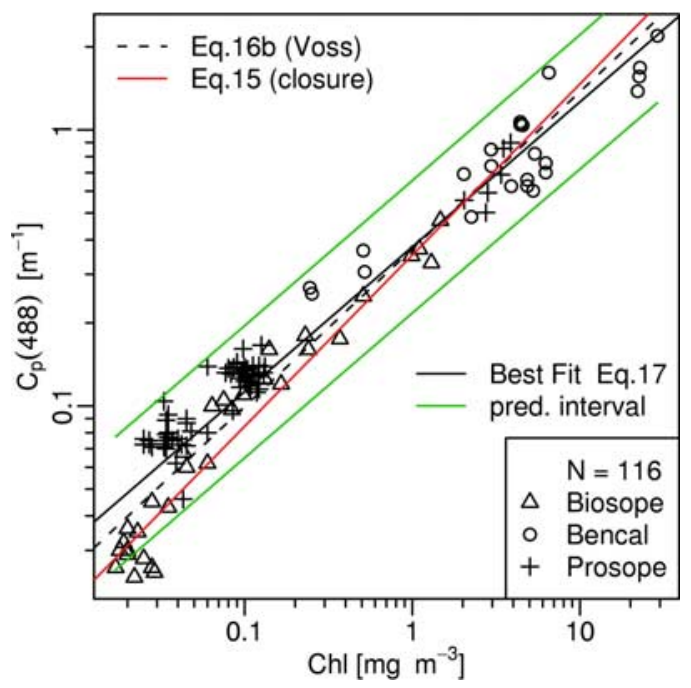

Figure 6. For recent field data (see Appendix), log-log plot of the particle attenuation coefficient at $488 \mathrm{~nm}, \mathrm{c}_{\mathrm{p}}$ as $\mathrm{m}^{-1}$ within the upper layer versus the contemporaneous local [Chl] value. The solid black line represents the best fit (equation (17)) with the 95\% prediction interval (green lines); the dashed line represents equation (16b) (modified from Voss [1992], see text); the red line (equation (15)) represents the closure.

[25] To account for the contribution of $\mathrm{a}_{\mathrm{y}}$ (generally not measured) to the total absorption, a parameterization, originally suggested by Prieur and Sathyendranath [1981], is often adopted in optical modeling. It consisted of assuming that the $a_{y}(440)$ term would be $20 \%$ of the sum $a_{p}(440)+$ $a_{w}(440)$, regardless of [Chl]. The ratio of $a_{y}$ to the sum $\left(a_{w}+\right.$ $a_{p}$ ) is displayed for several wavelengths (including $443 \mathrm{~nm}$ ) as a function of $[\mathrm{Chl}]$ in Figure 5. As expected, the relative $\mathrm{a}_{\mathrm{y}}$ contribution is larger for the short wavelengths (400 and $412 \mathrm{~nm}$ ), and then diminishing for 490 and $510 \mathrm{~nm}$. According to these data, the above parameterization for $440 \mathrm{~nm}$ does not seem appropriate, as on average it results in an underestimate of the relative influence of $\mathrm{a}_{\mathrm{y}}$. Indeed, from $\sim 20 \%$ at very low $[\mathrm{Chl}]\left(<0.05 \mathrm{mg} \mathrm{m}^{-3}\right)$, the relative contribution of $\mathrm{a}_{\mathrm{y}}(440)$ would increase up to $90 \%$, when [Chl] reaches $10 \mathrm{mg} \mathrm{m}^{-3}$. In this high [Chl] domain, $\mathrm{a}_{\mathrm{p}}$ and $\mathrm{a}_{\mathrm{y}}$ tend to be equal over a wide spectral domain $(420-500$ $\mathrm{nm}$ ), as already shown by Figure 4c. According to Figure 1, $a_{y}$ seems to remain proportional to $a_{p}$, and apparently is closer to this single term rather than to the sum $\left(a_{p}+a_{w}\right)$.

\subsection{Scattering, Absorption, and Attenuation}

\subsubsection{Tentative Closure}

[26] The closure (as specified by equation (6)) consists of summing the empirical expressions for $\mathrm{a}_{\mathrm{p}}(\lambda,[\mathrm{Chl}])$, and $\mathrm{b}_{\mathrm{p}}(\lambda,[\mathrm{Chl}])$, and verifying that this sum complies with relationships directly established between $\mathrm{c}_{\mathrm{p}}(\lambda,[\mathrm{Chl}])$ and [Chl]. The empirical relationship obtained by Voss [1992] was for $\lambda=490 \mathrm{~nm}$. At this wavelength, $\mathrm{a}_{\mathrm{p}}$ is related to [Chl] according to [Bricaud et al., 1998]

$$
\mathrm{a}_{\mathrm{p}}(490,[\mathrm{Chl}])=0.034[\mathrm{Chl}]^{0.62}
$$

For $b_{p}$, the first empirical relationships established for the upper layer and $\lambda=550 \mathrm{~nm}$, was that of Gordon and Morel [1983]

$$
\mathrm{b}_{\mathrm{p}}(550,[\mathrm{Chl}])=0.300[\mathrm{Chl}]^{0.62}
$$

When transferred from $\lambda=550$ to $490 \mathrm{~nm}$ (by using a $\lambda^{-0.5}$ law, see discussion below), the coefficient becomes 0.318 ; therefore, the sum $\left(a_{p}+b_{p}\right)$ amounts to

$$
\mathrm{c}_{\mathrm{p}}(490,[\mathrm{Chl}])=0.352[\mathrm{Chl}]^{0.62}
$$

while the relationship directly obtained by Voss [1992, Figure 6] was

$$
\mathrm{c}(490,[\mathrm{Chl}])-\mathrm{c}_{\mathrm{w}}(490)=0.39[\mathrm{Chl}]^{0.57}
$$

here $c_{w}$ stands for the attenuation coefficient by pure seawater. The difference $\left(c-c_{w}\right)$, however, is a slight overestimate of $c_{p}$, because the absorption by dissolved material, (i.e., $\left.a_{y}\right)$ remains included in $\left(c-c_{w}\right)$. This small term, estimated from equation (11) (and equation (12), with $\mathrm{S} \sim 0.015 \mathrm{~nm}^{-1}$ ) amounts to

$$
\mathrm{a}_{\mathrm{y}}(490,[\mathrm{Chl}]) \sim 0.02[\mathrm{Chl}]^{0.62}
$$

If considered as significant, it can be subtracted from equation (16a) (by neglecting the small difference in exponents), so that

$$
\begin{aligned}
\mathrm{c}(490,[\mathrm{Chl}])-\mathrm{c}_{\mathrm{w}}(490)-\mathrm{a}_{\mathrm{y}}(490,[\mathrm{Chl}])= & \mathrm{c}_{\mathrm{p}}(490,[\mathrm{Chl}]) \\
& \sim 0.37[\mathrm{Chl}]^{0.57}
\end{aligned}
$$

Since Voss has published his study, other determinations have been made. Exact estimates of $c_{p}$ are now obtainable by using simultaneously two ac-9 instruments, when one of them is equipped with a filter to determine $\mathrm{a}_{\mathrm{y}}$. By subtracting this term (as in equation (16b) above) an exact $c_{p}$ value (at $488 \mathrm{~nm}$ ) is derived. Field data from recent cruises in case 1 waters (see Appendix) and encompassing a wide [Chl] range $\left(0.02-30 \mathrm{mg} \mathrm{m}^{-3}\right)$ are displayed on Figure 6 . They confirm both the trends described by equations (15) or (16b). The best fit for these field data expresses

$$
\mathrm{c}_{\mathrm{p}}(488,[\mathrm{Chl}])=0.377[\mathrm{Chl}]^{0.53}
$$

with a rather large RMSE value $(0.277$, computed for the $\log _{10}$ transform), meaning that $\mathrm{c}_{\mathrm{p}}(488)$ can vary within a factor of about 3.5 for a given [Chl] value. Therefore, the slight numerical differences between equations (15), (16b), and (17) are not statistically significant. The closure can be considered as reasonably achieved as these three expressions (see Figure 6) actually coincide within their own confidence limits.

[27] For this comparison, emphasis was put on the specific wavelength $490 \mathrm{~nm}$. The results published by Loisel and Morel [1998] also dealt with the attenuation coefficient $c_{\mathrm{p}}(660,[\mathrm{Chl}])$. These authors, however, argued that the attenuation coefficient does not appreciably differ from the scattering coefficient, $b_{p}(660)$, because absorption 

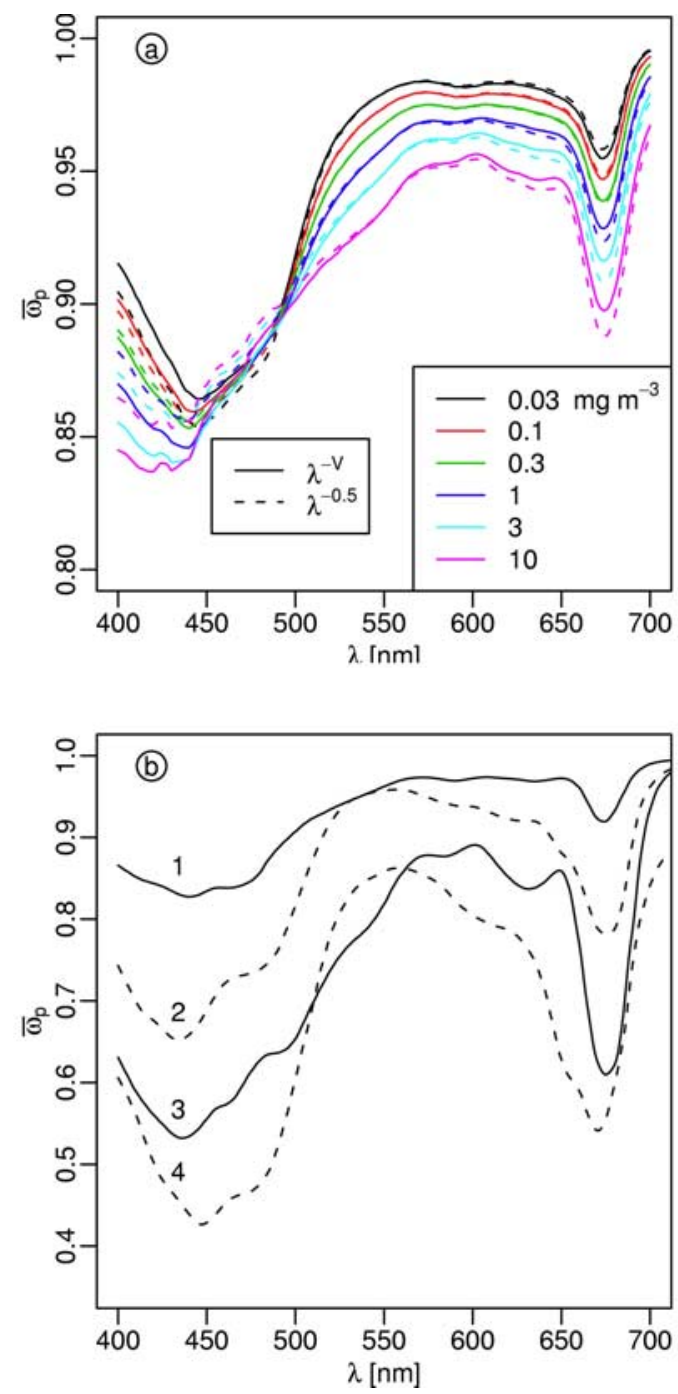

Figure 7. (a) Spectral values of the single scattering albedo of marine particles; The solid curves are derived by using equations (18) and (19); the dashed curves are derived by using a constant v-value (namely, -0.5 ) in equation (19). (b) For visual comparison, examples of single albedo of various phytoplankters grown in pure culture: 1, Emiliana huxleyi; 2, Dunaliella bioculata; 3, Hymenomonas elongata [from Ahn et al., 1992]; and 4, Prochlorococcus, strain "Sarg" [Morel et al., 1993]. Note the change in the ordinates scale from Figures $7 \mathrm{a}$ to $7 \mathrm{~b}$.

is comparatively negligible ( $3 \%$ at the most) at this wavelength. This is definitely true; but, in turn this $b_{p}(660)$ coefficient can no longer be legitimately used for testing the closure. For other wavelengths as 443 and $555 \mathrm{~nm}$ (results not shown), the conclusions are similar to those for $490 \mathrm{~nm}$, and the closure is similarly achieved. Anyway, a more complete (hyperspectral) approach is provided below by examining the magnitude and spectral shape of the particle scattering albedo.

\subsubsection{Particle Single Scattering Albedo Spectra}

[28] The empirical relationships providing $\mathrm{a}_{\mathrm{p}}(\lambda,[\mathrm{Chl}])$ and $b_{p}(\lambda,[C h l])$ are again reassembled to produce $\varpi_{p}(\lambda$, [Chl]), via equation (9). As for the spectral dependency of the particle scattering coefficient (namely the $\mathrm{B}_{0}(\lambda)$ term in equation (7)) another information is required. Many observations (Morel [1973], Russian measurements summarized by Shifrin [1983], see also review by Mobley [1994]) tend to prove that a $\lambda^{\nu}$ dependency is adequate for scattering by oceanic particles. The exponent $\nu$ actually is related to the size distribution function of the particle assemblage and was found on average to be equal to -1 [Morel, 1973]. More generally, it would be lying between -0.3 and -1.7 according to Kopelevich [1983], quoted by Mobley [1994]; the first value would be typical of populations including large particles and large algal cells (as found in eutrophic environments), and the second value typical of smaller particles populations (such as picoplankton and small debris in oligotrophic waters). Despite the difference between scattering and attenuation, the same exponent is often proposed to express the spectral variations of the attenuation coefficient [e.g., Boss et al., 2001].

[29] By accounting for a possible change in the exponent with the trophic state, and by relying on theoretical considerations regarding the particle phase function, it was proposed in MM01 [see also Morel et al., 2002] to introduce a varying exponent, thereafter denoted $\mathrm{v}([\mathrm{Chl}])$, regularly dependent on $[\mathrm{Chl}]$ according to

$$
\begin{aligned}
& \mathrm{v}([\mathrm{Chl}])=(1 / 2)\left(\log _{10}[\mathrm{Chl}]-0.3\right) \\
& \text { when } 0.02<[\mathrm{Chl}]<2 \mathrm{mg} \mathrm{m}-3 \\
& \mathrm{v}=0 \text { when }[\mathrm{Chl}]>2 \mathrm{mg} \mathrm{m}-3
\end{aligned}
$$

With this parameterization, $\mathrm{v}$ varies smoothly between -1 and 0 when [Chl] goes from 0.02 to $2 \mathrm{mg} \mathrm{m}^{-3}$, while the particle scattering becomes spectrally neutral when [Chl] exceeds $2 \mathrm{mg} \mathrm{m}^{-3}$. The spectral variations of $b_{p}$ are finally expressed according to

$$
\mathrm{b}_{\mathrm{p}}([\mathrm{Chl}], \lambda)=(\lambda / 550)^{\mathrm{v}([\mathrm{Chl}])} \mathrm{b}_{\mathrm{p}}([\mathrm{Chl}], 550)
$$

where $b_{p}([\mathrm{Chl}], 550)$ is expressed as in MM01 (their equation (12)). The resulting $\varpi_{p}(\lambda$, [Chl]) values, displayed in Figure $7 \mathrm{a}$, are not exclusively derived from empirical relationships since these computations have involved an assumption (namely equation (18)) about the spectral dependence of scattering. A consensus is not yet reached regarding this dependency and its variability (see, for instance, discussion by Huot et al. [2008]). For that reason, another simple working hypothesis was also adopted, that of a constant exponent, independent from [Chl] and let equal to the average value -0.5 .

[30] Not surprisingly, Figure $7 \mathrm{a}$ demonstrates that $\varpi_{p}$ keeps rather high values $(>0.85)$ throughout the spectrum, with the two expected minima in correspondence with the algal pigment absorption maxima, around 445 and $675 \mathrm{~nm}$. Using the varying exponent (from equation (18)), or the constant one does not appreciably change the global patterns. The relative position of the curves according to the [Chl] value can be explained. Near the maximal pigment absorption $(\sim 440 \mathrm{~nm})$ and within the $440-495 \mathrm{~nm}$ range, the exponents $\mathrm{B}_{\mathrm{p}}$ (in equation (1)) amount to $0.63( \pm 0.01)$, and thus are close to $\beta(\sim 0.62$, in equation (7)). As a consequence, the ratio $\varpi_{p}$ remains roughly unchanged when [Chl] varies. The residual minute changes result from the influence of the exponent $\mathrm{v}$ which slightly modulates the 
scattering. In contrast, within the zone where $\varpi_{p}$ is maximal $(560-630 \mathrm{~nm})$, the $\mathrm{B}_{\mathrm{p}}$ exponents are larger $(\sim 0.85)$ than the approximately constant exponent for scattering $(\beta \sim 0.62)$. Consequently, for increasing [Chl], absorption increases more than scattering, with the result of a significant lowering of $\varpi_{p}$. In total, (except around a hinge point around $470 \mathrm{~nm}$ ), the scattering albedo generally decreases throughout the whole spectrum for increasing algal concentration. This mean that on average the particle assemblages are globally more "colored" when [Chl] is large, and less colored when [Chl] is low. These results can be useful starting points for optical modeling purposes.

[31] Experimental $\mathrm{c}(\lambda)$ and $\mathrm{a}(\lambda)$ values for phytoplankters grown in culture [Ahn et al., 1992; Bricaud et al., 1988; Stramski et al., 2001] can also be used to produce $\varpi_{p}(\lambda)$ spectra (Figure 7b). If their shapes and spectral features resemble those in Figure $7 \mathrm{a}$, their values are, as logically expected, lower. Indeed, spectra for natural assemblages, including (beside algae) a detrital retinue of weakly or nonpigmented scattering particles, cannot reproduce those, more featured, of pure living algae. The resulting heightening and flattening of the $\varpi_{p}$ spectra due to detrital particles, is systematically observed in natural environments [Babin et al., 2003].

\subsection{Spectral Reflectance, $\mathbf{R}(\lambda,[\mathrm{Chl}])$, and the Backscattering Issue}

[32] A comparison between the strictly empirical algorithms for the [Chl] retrieval, namely, OC4v4 and OC $3 \mathrm{M}$ (developed for SeaWiFS and MODIS-A, respectively), and the semianalytical MM01 reflectance model which has led to the OC4Me algorithm (developed for MERIS) was presented in detail elsewhere [Morel et al., 2007c, Figures 1 and 2], and is not repeated here. Suffice it to recall that there is an excellent agreement between these algorithms in terms of [Chl] returns over most of the [Chl] range. In the frame of the present study, this agreement basically means that compatibility exists between the direct empirical relationships $\mathrm{R}_{\mathrm{j}}^{\mathrm{i}} \leftrightarrow[\mathrm{Chl}]$ (i.e., equation (10), with coefficients by O'Reilly et al. [2000]), and the independent relationships (equations (2) and (7), plus additional assumptions of equation (18)) which are combined to predict the $\mathrm{R}_{j}^{1} \leftrightarrow[\mathrm{Chl}]$ semiempirical relationships. Another test is possible by comparing the two semianalytical models MM01 and GSM, which are both applicable to case 1 waters, but differ in terms of involved relationships. In particular, GSM, purposely developed to retrieve some inherent optical properties, allows independent estimates of $\mathrm{a}_{\mathrm{CDM}}(440)$ and [Chl] via $\mathrm{a}_{\varphi}(\lambda)$. In contrast, in the MM01model initially based on $\mathrm{K}_{\mathrm{d}}$, the components of absorption are not explicitly involved nor separated, and $\mathrm{a}_{\mathrm{y}}$ is thus ignored.

[33] To test the consistency of the two (GSM and MM01) approaches, the GSM inversion process is applied to the $\mathrm{R}(\lambda,[\mathrm{Chl}])$ spectra produced by MM01 with [Chl] as input and at the wavelengths considered in GSM. By doing so, $\mathrm{a}_{\mathrm{CDM}}$, not explicitly involved in MM01, can be assessed through GSM as a function of the [Chl] values that were used as inputs in MM01. These $\mathrm{a}_{\mathrm{CDM}}(440$, [Chl]) returns are to be compared to those previously obtained by difference (Figure 1 and equation (11)). The result of the MM01 reflectances inversion is shown on Figure 8a. The agreement between the two approaches is striking; in particular,
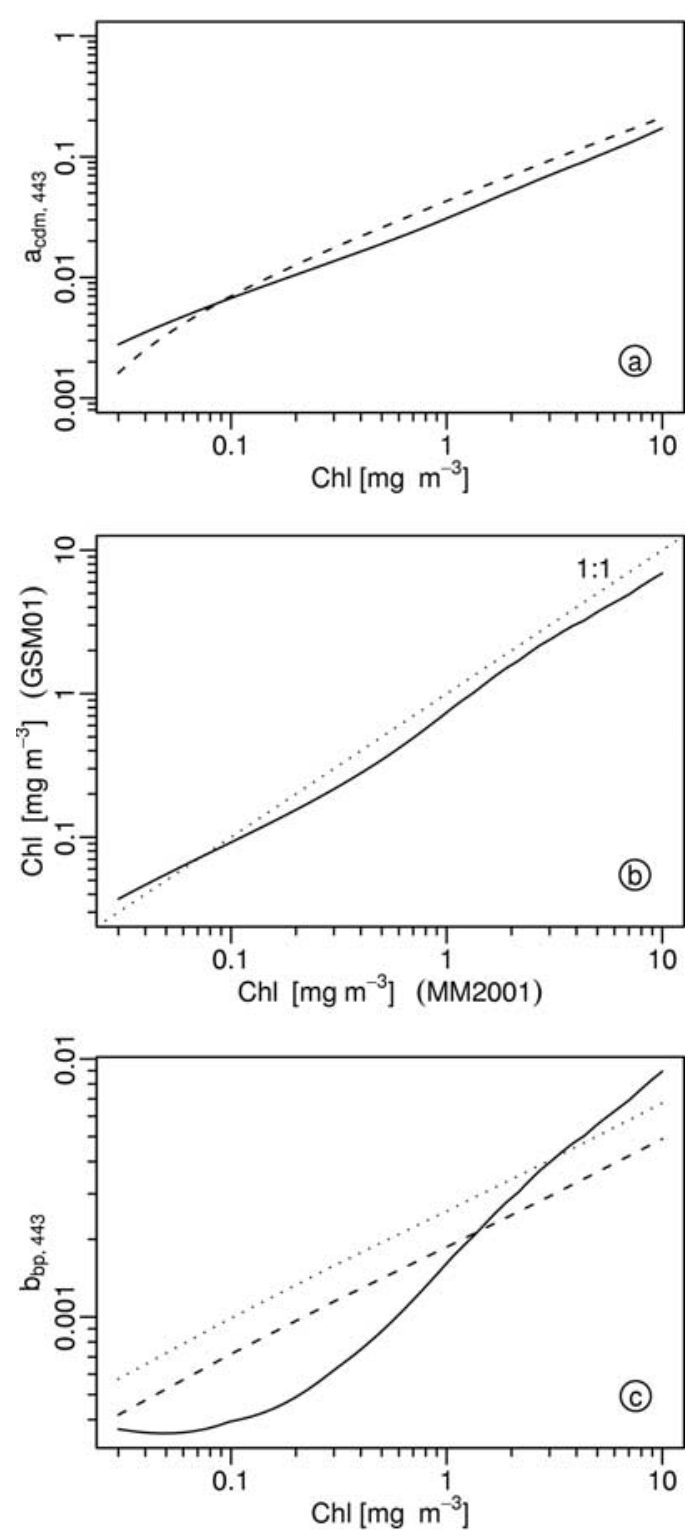

Figure 8. Application of the Garver, Siegel, and Maritorena (GSM) inversion scheme to the reflectance spectra modeled (using MM01 model) as a function of [Chl] to retrieve the colored detrital material absorption, $\mathrm{a}_{\mathrm{CDM}}(443)$, [Chl] and the particle backscattering, $b_{b p}(443)$. (a) The solid curve represents $\mathrm{a}_{\mathrm{CDM}}(443)$, to be compared to the dashed curve (reproduced from Figure 1c) showing the $\mathrm{a}_{\mathrm{y}}(443)$ values; (b) [Chl] retrieved via GSM, as a function of the [Chl] values used as inputs to produce the reflectance spectra; (c) $b_{b p}(443)$ retrieved via GSM (solid curve), compared to $b_{b p}(443)$ values (dotted curve) used in MM01 to produce the reflectance spectra submitted to the GSM inversion. The dashed curve derives from the dotted one with a lower $\mathrm{B}_{0}$ coefficient (in equation (7)); this value results from the partial statistical analysis [Loisel and Morel, 1998] when their subset 1 is removed.

the nonlinear $\mathrm{a}_{\mathrm{CDM}}$ and $\mathrm{a}_{\mathrm{y}}$ increases with increasing [Chl] are expressed by about the same exponent $(\sim 0.63)$. In principle, $\mathrm{a}_{\mathrm{y}}$ is expected to be smaller than $\mathrm{a}_{\mathrm{cdm}}$; actually, it is slightly larger by about $25 \%$, at least when [Chl] $>$ 
$0.1 \mathrm{mg} \mathrm{m}^{-3}$; below this value the convexity, already suspected to result from an artifact, is not supported by the $\mathrm{a}_{\mathrm{cdm}}$ regular decrease.

[34] The [Chl] values, retrieved through the GSM inversion applied to the spectra produced by the MM01 model, can be compared with the [Chl] values used as inputs in the model. The results (Figure $8 \mathrm{~b}$ ), which prove to be satisfactorily, are only presented for the sake of completeness; indeed, this comparison does not bring any additional information about the relationships consistency. As for the backscattering coefficient (Figure 8b), the values introduced into the MM01 model to produce the [Chl]-dependent reflectance are not retrieved by GSM. Actually, the assumptions made in each model differ; in particular, the spectral behavior of $b_{b p}$ is expressed through equation (18) in MM01, while the exponent is fixed $(=-1.0037)$ in GSM, so that diverging results are expected.

[35] In semianalytical modeling (via equation (4)), there is a need to dispose of a relationship (if it exists) between the particle backscattering coefficient $b_{b p}$, and [Chl] in case 1 waters. So far, such a relationship has been replaced by plausible assumptions supported by theoretical considerations [Gordon et al., 1988, equation 12; Morel and Maritorena, 2001, equation 13; Ulloa et al., 1994]. As the scattering coefficient, $b_{p}$, is reasonably well related to [Chl] in case 1 waters (equation (7)), the backscattering coefficient would be related to $[\mathrm{Chl}]$ provided that the backscattering ratio, $\widetilde{b}_{b p}\left(=b_{b p} / b_{p}\right)$, is sufficiently stable. Such an approximate stability might reasonably be expected to the extent that the watery particles, all of biogenous origin, have an index of refraction (relative to water) varying within a rather narrow range, (say, 1.03-1.07, except for coccoliths), also to the extent that particle size distributions of the Junge type with an exponent around 4 seem to prevail in oceanic environment. Under such conditions, theoretical calculations show that $\widetilde{\mathrm{b}}_{\mathrm{bp}}$ is of the order of 0.5 to $1.5 \%$ [Twardowski et al., 2001, Figure 1; Morel and Maritorena, 2001, Figure 9]. Recently published field data for case 1 waters support such values; on average, $\widetilde{\mathrm{b}}_{\mathrm{bp}}$ would amount to about $0.96 \%$ [Twardowski et al., 2001], or to 0.7-0.8\% [Huot et al., 2008]. With such a roughly constant backscattering ratio, $b_{b p}$ and $b_{p}$ must be related to [Chl], in a similar manner, i.e., according to the same power function (as in equations (7) and (14)).

\subsection{Case 1 Waters Variability: Individual Data Versus Average Relationships}

[36] The computational scheme used for the generic average relationships (equations (1), (2), (3), and (5)) can also be applied on a case-per-case basis to field data, namely, to recent simultaneous determinations (of $a_{p}(\lambda)$, $\mathrm{c}_{\mathrm{p}}(488), \mathrm{K}_{\mathrm{d}}(\lambda), \mathrm{R}(\lambda)$ ) which were in no way involved in the production of the empirical relationships (equations (1) and (2)); therefore, these examples are significant and not making up a circular argument. Actually, the comparison between the average trends (Figures 1) and the individual data are not intended to be a validation; on the contrary, the distribution of these data with respect to the average trends is used to provide information about the possible bio-optical variability naturally occurring in case 1 waters.

[37] The contemporaneous sun-zenith angle, $\theta_{\mathrm{s}}$, and the individual $\mathrm{K}_{\mathrm{d}}(\lambda), \mathrm{R}(\lambda)$ measurements, are introduced into equation (3) to derive the local $a_{\text {tot }}(\lambda)$ values. The $a_{p}(\lambda)$ values determined in the upper layer at the same station are subtracted from $a_{\text {tot }}(\lambda)$ to obtain the local $a_{y}(\lambda)$ values (equation (5)). Such a case-per-case process was applied in the UV domain $(370 \mathrm{~nm})$ to some data in eutrophic and oligotrophic waters [Morel et al., 2007a], and this technique is here extended to the blue-to-green part of the spectrum, and to other recent available field data (see Appendix).

[38] Individual $\left(a_{p}+a_{w}\right)$ data are displayed in Figure 9, whereas the mean $\left(a_{p}+a_{w}\right)$ curves are simply reproduced from Figure 1. The scatter of these data with respect to the mean curves is similar to that existing in the original analysis [Bricaud et al., 1998] which led to equation (1) (see RMSE in Appendix). The individual $\mathrm{a}_{\mathrm{y}}(\lambda)$ values, as displayed in Figure 10, conform to the general trends represented by the $\mathrm{a}_{\mathrm{y}}(\lambda)$ curves redrawn from Figure 1. A considerable scatter occurs, particularly at low [Chl], which may partly originate from variability in $a_{p}$, (or as well from inaccurate $a_{p}$ determinations). This dispersion, however, likely reflects a true natural variability in the $\mathrm{a}_{\mathrm{y}}(\lambda) \leftrightarrow$ [Chl] relationship. Actually, such a variability was observed when considering the UV spectral domain, and consisted of deviations in the $\mathrm{a}_{\mathrm{y}} \leftrightarrow[\mathrm{Chl}]$ relationship systematically occurring in certain zones, as in the Mediterranean and Pacific waters [Morel et al., 2007a]. These systematic deviations, particularly ostensible in the UV domain, are still present in the visible domain (Figure 10). They are at the origin (and perhaps are the main cause) of bio-optical variability in case 1 waters, and reflect the lack of a tight covariation between dissolved absorption and contemporaneous algal absorption

[39] The natural variability in the $\mathrm{a}_{\mathrm{y}} \leftrightarrow[\mathrm{Chl}]$ relationship can also be documented by using direct determinations. The International Ocean Colour Coordinating Group (IOCCG) [2006] data set which includes simultaneous field measurements of $\mathrm{a}_{\mathrm{y}}(411)$ and [Chl] can be considered for this purpose. These $\mathrm{a}_{\mathrm{y}}$ data (Figure 10e) roughly exhibit the same trend along the [Chl] range as previously established. The wide dispersion probably reflects the inaccuracies attached to the difficult $\mathrm{a}_{\mathrm{y}}$ determinations, especially at low values [e.g., Nelson et al., 1998, Figure 1b]. Recall that the photometric accuracy of sensitive spectrophotometers is about 0.0005 OD (optical density), equivalent to an absorption coefficient of $0.01 \mathrm{~m}^{-1}$ when a $10 \mathrm{~cm}$ cuvette is used [Nelson et al., 1998; Mueller and Fargion, 2002]. Actually, the field data do not cross this lower limit which is of instrumental nature. In addition, "most of these data (extracted from the SeaBASS Archive) [Hooker et al., 1994] come from locations that are relatively close to the coast" [IOCCG, 2006], so that the rather high $\mathrm{a}_{\mathrm{y}}$ values along the whole [Chl] range are not surprising. When used in the same way, the NOMAD data set [Werdell and Bailey, 2005 ] produces the same kind of pattern (not shown), with a similar scatter.

\section{Discussion and Conclusion}

[40] The exponential slope $\left(\mathrm{S}<0.01 \mathrm{~nm}^{-1}\right.$ when [Chl] $>$ $1 \mathrm{mg} \mathrm{m}^{-3}$ ) which expresses the spectral behavior of the $\mathrm{a}_{\mathrm{y}}$ term seems particularly low when compared to literature values [see, e.g., Twardowski et al., 2004]. Higher slope values seem to prevail for lower [Chl], but in this case the 

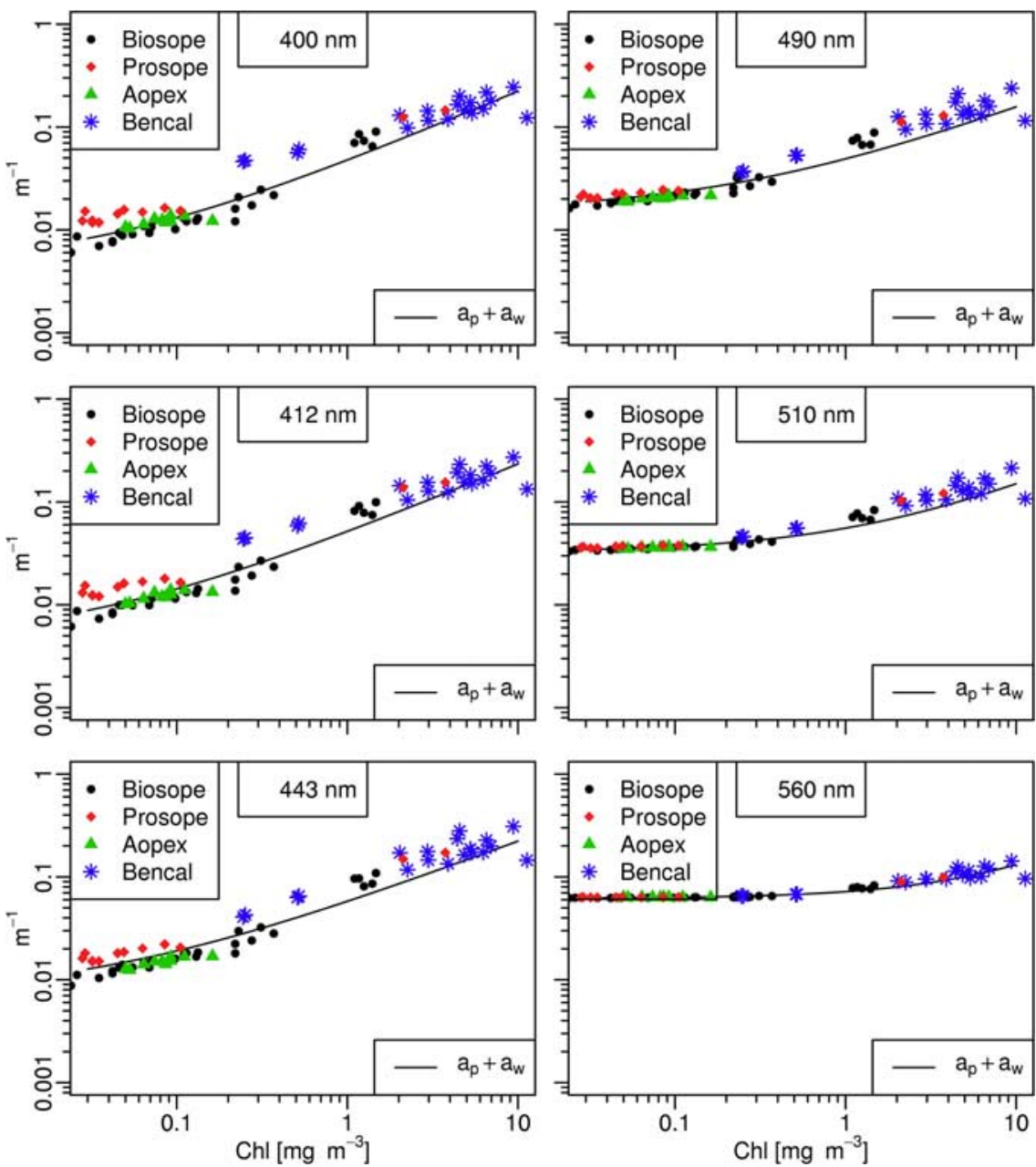

Figure 9. For various wavelengths as indicated, plot as a function of [Chl] of the quantity $a_{p}+a_{w}$ (particle absorption plus water absorption), computed for individual data (stations from four recent cruises, with colored symbols as indicated). These data are to be compared to the average $\left(a_{p}+a_{w}\right)$ curves, reproduced from Figure 1.

spectral range (see Figure 2) is severely limited, so that the derivation of $\mathrm{a}_{\mathrm{y}}(\lambda)$ from $\mathrm{a}_{\mathrm{tot}}(\lambda)$ (i.e., from $\mathrm{K}_{\mathrm{d}}(\lambda)$ and $\mathrm{a}_{\mathrm{p}}(\lambda)$, becomes problematic. Note that the empirical relationships (equations (1) and (2)) were established from separate measurements of $a_{p}$ and $K_{d}$, thus their respective RMSE (Appendix) are independent. This is not the case in natural environments, however; if $a_{p}-K_{d}$ couples could be considered, correlations between their deviations would inevitably appear, although they are presently not quantifiable. Beside the possible bias and numerical uncertainties, there is also a problem of methodological nature. Indeed, there is no clear-cut distinction between what are called "dissolved" and "particulate" materials; in addition, the respective protocols to collect these materials [see, e.g., Mueller and Fargion, 2002] might introduce a significant bias. Glass-fiber filters (GF/F Whatman) are used to collect the particles in order to determine the absorption spectrum. Their pore size is not precisely known as it may vary according to the volume filtered and the progressive clogging of the filter. It is probably comprised between 0.7 (nominal size) and $0.5 \mu \mathrm{m}$ (discussions by Chavez et al. [1995] and Nelson et al. [1998]). In contrast, the determi- nation of the spectral absorption by the dissolved (and colloidal) fraction is currently performed after a removal of the particulate material by filtration through membrane filters, with $0.2 \mu \mathrm{m}$ pore size. Therefore, there is an imprecisely defined fraction of absorbing particulate material (between, say 0.2 and $0.5 \mu \mathrm{m}$ ) that is not included in the $a_{p}$ term, although it is reintroduced in the present " $a_{y}$ " term as an operational consequence of equation (5). This term might differ from, and in principle must exceed, the true dissolved absorption, as commonly measured when following normal protocols. The nonalgal particle absorption, $\mathrm{a}_{\text {nap }}$ (Figures 4) distinctly exhibits a less steep spectral slope than $\mathrm{a}_{\mathrm{y}}$ [Roesler et al., 1989; Bricaud et al., 1998]. To the extent that the fraction of the particle population inside the $0.2-0.5 \mu \mathrm{m}$ size interval would spectrally behave as $a_{\text {nap }}$, the $a_{y}$ term which includes this fraction will have a slope globally reduced. This effect would be significant for high [Chl] waters, which is perhaps a real fact, but a computational artifact cannot be excluded.

[41] In contrast, the significance of the mean relationship between $\mathrm{a}_{\mathrm{y}}(400)$ and [Chl] (equation (11)) is safer and more reliable, essentially because the retrieval of $\mathrm{a}_{\mathrm{y}}$ is numerically 

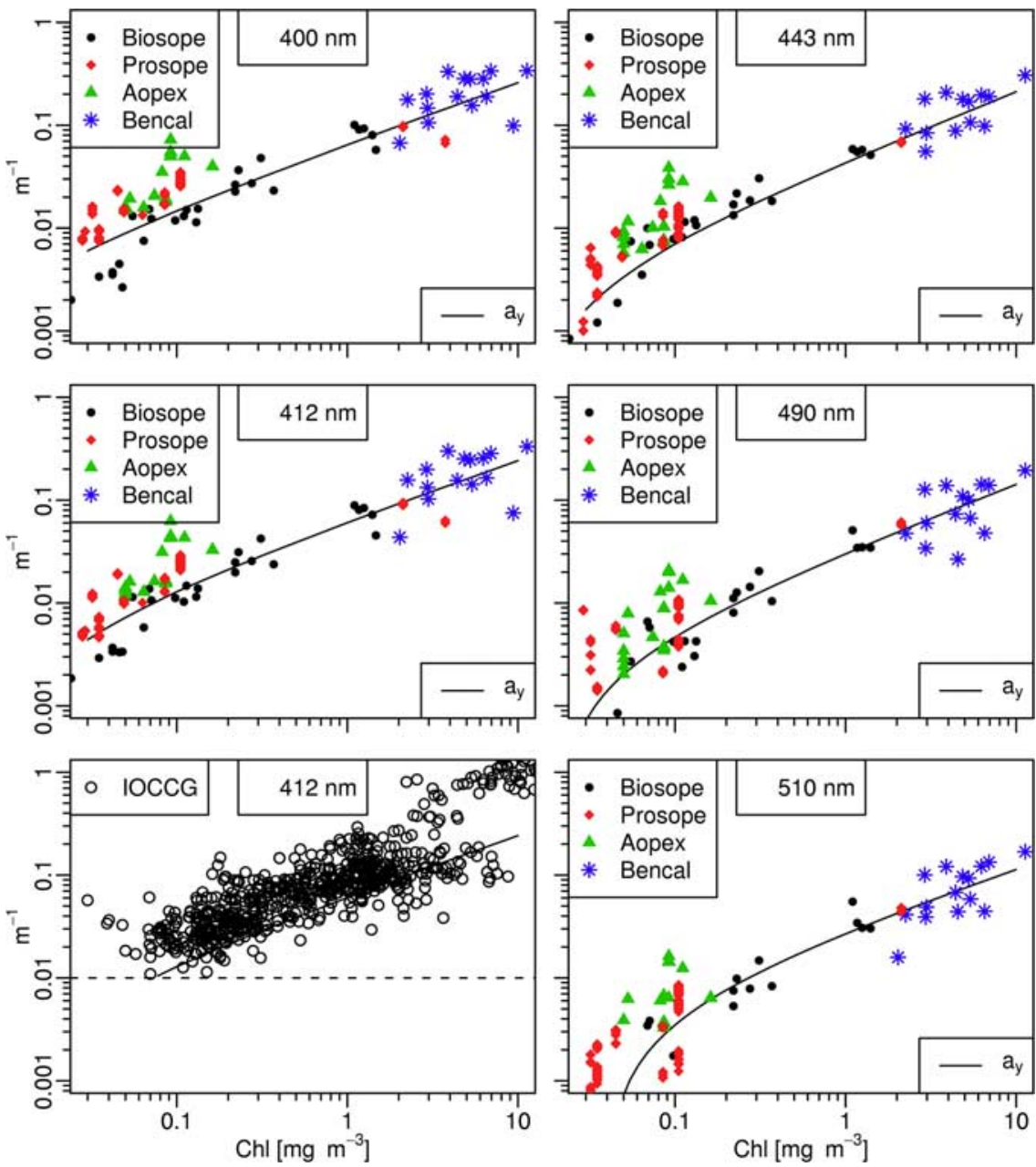

Figure 10. For the same wavelengths as in Figures 1 and 9 (apart from $560 \mathrm{~nm}$ ), plot of the individual $\mathrm{a}_{\mathrm{y}}$ values as a function of [Chl]. These $\mathrm{a}_{\mathrm{y}}$ values (colored symbols as in Figure 9) are retrieved by inversion and use of equations (3) and (5) together with the local determinations of $a_{p}, K_{d}, R$ and $\theta_{s}$. These $\mathrm{a}_{\mathrm{y}}$ values are overlaid on the average $\mathrm{a}_{\mathrm{y}}$ curves redrawn from Figure 1 . Also overlaid on the same curve for $\lambda=412 \mathrm{~nm}$, the $\mathrm{a}_{\mathrm{y}}$ and [Chl] data taken from the in situ IOCCG data set (available on the IOCCG Web site). The horizontal dashed line at $0.01 \mathrm{~m}^{-1}$ shows the detection threshold of highsensitivity spectrophotometers used with $10 \mathrm{~cm}$ path length.

more stable in this spectral domain. When this relationship is transferred to $440 \mathrm{~nm}$ by using a slope value of $0.018 \mathrm{~nm}^{-1}$ it becomes

$$
\mathrm{a}_{\mathrm{y}}(440)=0.032[\mathrm{Chl}]^{0.63}
$$

and it is interesting to note that this relationship agrees nicely with the $\mathrm{a}_{\mathrm{CDM}}(440) \leftrightarrow[\mathrm{Chl}]$ relationship (correlation coefficient $\mathrm{r}=0.751$ ) graphically displayed by Siegel et al. [2005b] Their figure (Figure 3a), based on 5-year global climatologies of ocean color data), supports the fact that "over wide expanses of the sea, there is fair correspondence between CDM and [Chl]" (ibid.). Actually, the dispersion in Siegel et al.'s Figure $3 \mathrm{a}$ suggests that $\mathrm{a}_{\mathrm{CDM}}$ is related to [Chl] within a factor of about 4 , i.e., a range similar to that derived from the consideration of the RMSE (see Appendix) for both equations (1) and (2), from which $\mathrm{a}_{\mathrm{y}}$ derives.

[42] The magnitude of $\mathrm{a}_{\mathrm{y}}$ appears to be larger than oft anticipated (Figures 3 and 4), but in agreement with some old [e.g., Bricaud et al., 1981] as well as recent findings
[Siegel et al., 2002, 2005a]. The comparison with Siegel et al.'s [2002, 2005a] studies is possible, albeit not straightforward, because they considered the absorption (denoted $\mathrm{a}_{\mathrm{CDM}}$, at $440 \mathrm{~nm}$ ) resulting from both dissolved and particulate detrital materials. Consequently, $\mathrm{a}_{\mathrm{CDM}}$, would be equivalent to the present sum $\left(\mathrm{a}_{\mathrm{y}}+\mathrm{a}_{\mathrm{nap}}\right)$. Siegel et al. [2002] also define the quantity "\%CDM," as

$$
\% \mathrm{CDM}=100 . \mathrm{a}_{\mathrm{CDM}}(440) /\left[\mathrm{a}_{\mathrm{CDM}}(440)+\mathrm{a}_{\varphi}(440)\right]
$$

or

$$
\begin{aligned}
\% \mathrm{CDM}= & 100 .\left[\mathrm{a}_{\mathrm{y}}(440)+\mathrm{a}_{\text {nap }}(440)\right] \\
& /\left[\mathrm{a}_{\mathrm{y}}(440)+\mathrm{a}_{\text {nap }}(440)+\mathrm{a}_{\varphi}(440)\right]
\end{aligned}
$$

with the present notations. When computed by using the data displayed in Figures 4, this \%CDM amounts to 58, 57, 55,51 and $45 \%$, for $[\mathrm{Chl}]=10,3,1,0.3$ and $0.1 \mathrm{mg} \mathrm{m}^{-3}$, respectively. These values compare favorably with the 
Table A1. Source Papers or Web Sites for the Bio-optical Relationships and Parameters Used in the Present Study ${ }^{\mathrm{a}}$

\begin{tabular}{|c|c|c|}
\hline Relationship & Quantity & References \\
\hline Equation $1^{\prime b}$ & $a_{p}(\lambda)$ & Bricaud et al. [1995, Table 2]; revised in the work by Bricaud et al. [1998] \\
\hline Equation $1^{\mathrm{c}}$ & $a_{p}(\lambda)$ & Bricaud et al. [1998] "coefficients provided on request" (page 31037) \\
\hline Equation $2^{\mathrm{d}}$ & $\mathrm{K}_{\mathrm{d}}(\lambda)$ & $\begin{array}{l}\text { Morel [1988, Table 2]; Morel and Maritorena [2001, Table 2]; entire LOV data set available at } \\
\mathrm{ftp} / / / \text { oceane.obs-vlfr.fr/pub/morel/2006-e6-chi; Morel et al. }[2007 \mathrm{c} \text {, Table 4] (NOMAD + LOV) }\end{array}$ \\
\hline Equation $3^{\mathrm{e}}$ & $\mathrm{f}^{\prime}, \mu_{\mathrm{d}}, \mathrm{R}$ & $\begin{array}{l}\text { LUT for as function of } \lambda, \theta_{\mathrm{s}} \text {, and [Chl] available at ftp://oceane.obs-vlfr.fr/pub/morel, } \\
\text { see filesf.dat,fp.dat,mud.dat }\end{array}$ \\
\hline Equation $8^{\mathrm{f}}$ & $\mathrm{c}(\lambda),[\mathrm{Chl}]$ & Voss $[1992]$ \\
\hline Equation $10^{\mathrm{g}}$ & {$[\mathrm{Chl}], \mathrm{R}_{\mathrm{j}}^{\mathrm{i}}$} & $\begin{array}{l}\text { O'Reilly et al. [1998], revised by O'Reilly et al. [2000] for OC4, OC2 (and OC3) algorithms; } \\
\text { Morel et al. [2007c] for OC4Me algorithms }\end{array}$ \\
\hline Equation $14^{\mathrm{h}}$ & $b_{p}(\lambda)$ & Gordon and Morel [1983]; Loisel and Morel [1998] \\
\hline Figure $9 b^{i}$ & [Chl], $\mathrm{a}_{\mathrm{g}}$ & In situ data set selected by IOCCG [2006] \\
\hline Figures $9 \mathrm{a}$ and $9 \mathrm{~b}^{\mathrm{j}}$ & {$[\mathrm{Chl}], \mathrm{a}_{\mathrm{p}}, \mathrm{K}_{\mathrm{d}}, \mathrm{R}$} & References for the recent cruises \\
\hline
\end{tabular}

${ }^{\mathrm{a}}$ Data, uncertainties and statistical information provided as comments.

${ }^{\mathrm{b}}$ Statistical analysis on $\mathrm{N}=815$ samples.

${ }^{\mathrm{c}} \mathrm{N}=1166$ samples, statistical analyses of both $\mathrm{a}_{\mathrm{p}}(\lambda)$ and $\mathrm{a}_{\varphi}(\lambda)$, with [Chl] from 0.03 to $25 \mathrm{mg} \mathrm{m}^{-3}$; the RMSE for $\mathrm{a}_{\mathrm{p}}(\lambda)$, , computed for the $\log _{10^{-}}$ transform data, are between $\sim 0.16(\lambda=400-500 \mathrm{~nm}), 0.18(510 \mathrm{~nm})$, and $0.27(555 \mathrm{~nm})$; similar values for $\mathrm{a}_{\varphi}(\lambda)$.

${ }^{\mathrm{d}}$ The initial $\chi(\lambda)$ and $\mathrm{e}(\lambda)$ values (equation (2)) were derived from the statistical analysis of about 205 couples of spectral diffuse attenuation coefficients, $\mathrm{K}_{\mathrm{d}}(\lambda)$ and [Chl] [see Morel, 1988, Table 1]; this data set was increased up to 326 couples for the subsequent study [Morel and Maritorena, 2001, Table 1]. The analysis of the present entire data set (denoted "LOV" data set, which contains about 435 couples), does not significantly modify the $\chi(\lambda)$ and e $(\lambda)$ values previously (2001) obtained. In the near UV domain $(350-415 \mathrm{~nm})$, the adopted $\mathrm{K}_{\mathrm{w}}(\lambda)$ values are slightly amended according to a recent reexamination of the pure water absorption [Morel et al., 2007b]. The Table providing the corresponding $\mathrm{K}_{\mathrm{w}}(\lambda), \chi(\lambda)$, e $(\lambda)$, and RMSE values is available by fttp (see address above); RMSE are between $0.127,0.106$, and 0.068 (at 400, 443, and $560 \mathrm{~nm}$, respectively). Note also that for the wavelengths used in ocean color remote sensing (also used in Figure 1), the $\chi(\lambda)$ and $\mathrm{e}(\lambda)$ values derived after merging the LOV data set and the independent NOMAD data set [Werdell and Bailey, 2005] are practically undistinguishable from those obtained with the sole LOV data set, except a slight increase of the RMSE [see Morel et al. 2007b, Table 4].

${ }^{\mathrm{e}}$ Origin and explanations for this lookup table are to be found in the works by Morel et al. [2002] and Morel and Gentili [2004].

${ }^{\mathrm{f}} \mathrm{N}=103$ simultaneous data for $\left(\mathrm{c}-\mathrm{c}_{\mathrm{w}}\right)$ at $490 \mathrm{~nm}$ and [Chl] varying from 0.05 to $10 \mathrm{mg} \mathrm{m}^{-3}$ [Voss, 1992]; for the present (LOV) data (equation (17)) $\mathrm{N}=$ $137, \mathrm{c}_{\mathrm{p}}(488)$ and [Chl] from 0.02 to $30 \mathrm{mg} \mathrm{m}^{-3}, \mathrm{r}^{2}=0.9347$, RMSE $=0.277$ (on log transform data); for the cruises (see comment $\mathrm{j}$ below.

${ }^{g} \mathrm{~N}=2853$ contemporaneous remote spectral remote sensing reflectance and [Chl] data.

${ }^{\mathrm{h}} \mathrm{N}=506$ simultaneous data in case 1 waters for [Chl] and b at $550 \mathrm{~nm}, \mathrm{r}^{2}=0.898$ for log transform data (Gordon and Morel [1983], data from 1970 to 1979); $\mathrm{N}=2787$ [Chl]- $\mathrm{c}_{\mathrm{p}}(660)$ data from 1989 to 1996; 850 for the upper layer only, with $\mathrm{r}^{2}=0.88$ [Loisel and Morel, 1998].

${ }^{\mathrm{i}}$ The in situ data set $(\mathrm{N}=656)$ available on the IOCCG site, is extracted from NASA's SeaWiFS Bio-optical Archive and Storage System SeaBASS, [Hooker et al., 1994]; the extraction was made by Z. P. Lee, Chairman of the Ocean Color Argorithms Working Group [2006], set up by IOCCG.

${ }^{\mathrm{j}}$ The recent cruises are PROSOPE (1999, Moroccan upwelling and Mediterranean Sea), BENCAL (2002, Benguela current), AOPEX (2004, Western Mediterranean Sea), and BIOSOPE (2004, Eastern South Pacific). Data and information for PROSOPE and BIOSOPE are available at www.obs-vlfr/proof; for AOPEX on http://www.ifremer.fr/sismer; and for the BENCAL cruise in a cruise report, NASA Technical Memorandum 2003-206892.

global mean value of 51\% given by Siegel et al. [2005b]. These values also indicate that on average, blue light absorption $(440 \mathrm{~nm})$ would be almost equally shared by phytoplankton and CDM, whatever the trophic level.

[43] The GSM inversion applied to the modeled reflectance spectra (Figure 8a) leads to $\mathrm{a}_{\mathrm{CDM}}$ values slightly below the $\mathrm{a}_{\mathrm{y}}$ values retrieved from $\mathrm{K}_{\mathrm{d}}$ (when $[\mathrm{Chl}]$ is $>$ $0.1 \mathrm{mg} \mathrm{m}^{-3}$ ). This result is the converse of what is expected since the absorption by colored detrital particles is included in $\mathrm{a}_{\mathrm{CDM}}$, whereas only a fraction of this term is included in $\mathrm{a}_{\mathrm{y}}$. The GSM inversion is constrained by the constant spectrum adopted for the chlorophyll-specific algal absorption. The values adopted by Maritorena and Siegel [2006] are considerably larger than those in Bricaud (1995-1998), (by $50 \%$ at $443 \mathrm{~nm}$ when $[\mathrm{Chl}]=1 \mathrm{mg} \mathrm{m}^{-3}$, for instance, and even more when [Chl] increases). Therefore the room left for $\mathrm{a}_{\mathrm{CDM}}$ would be narrowed, which is perhaps an explanation for the slight divergence that is observed. The complexity of the nonlinear least square fit imbedded in GSM inversion may conceal other causes for discrepancies.

[44] In conclusion, a globally positive answer can be given to the initial question of the internal consistency and compatibility that was raised in the title. Within their own uncertainty levels, the available empirical expressions which were independently derived for various inherent and apparent optical properties $\left(a_{p}(\lambda), b_{p}(\lambda), c_{p}(\lambda), R(\lambda)\right.$, and $\mathrm{K}_{\mathrm{d}}(\lambda)$ ), and which relate these coefficients to [Chl], form to a first order an internally coherent set of equations, over a wide [Chl] range and over the blue and green spectral domain. As a by-product of this study, the absorption term due to colored dissolved matter, $\mathrm{a}_{\mathrm{y}}$, has been derived. Its magnitude is more important than generally modeled, and it was found on average to be roughly proportional to $[\mathrm{Chl}]^{0.6}$ over approximately the full [Chl] range. Such a dependency could be seen as a "standard" for case 1 waters, while the variability around this standard would be the most probable cause of the major deviations in the bio-optical properties in these waters [Siegel et al., 2002; Brown et al., 2008].

[45] Independently from the question of the usefulness of an optical classification [Mobley et al., 2004], it remains certainly worthwhile to improve the knowledge of the biooptical properties of case 1 waters, and to verify their mutual compatibility as well as the degree of consistency attainable under the hypothesis of bio-optical properties related to [Chl]. The present approach is based on statistical analyses and not on physical considerations. In total, however, the empirical relationships developed during the last decades and presently available, provide a coherent frame within which the bio-optical properties of case 1 waters can be expressed, their variability assessed, and robust empirical models built.

\section{Appendix A}

[46] The bio-optical relationships, parameters, and field data used in the present study originate from various studies 
and field operations. The corresponding source papers are recapitulated in the appended Table $\mathrm{A} 1$, in reference to the equations as they are numbered in the text. For convenience, information such as number and nature of data, location, statistical analyses and significance, uncertainties are extracted from original papers, and summarized in the footnotes of Table A1.

[47] Acknowledgments. Bernard Gentili was instrumental in taking care of the data archive, in statistically analyzing these data, and finally preparing the illustrations. He is particularly thanked for his continuous effort. I am also indebted to Marcel Babin and Yannick Huot for pertinent comments on preliminary drafts of the present paper.

\section{References}

Ahn, Y.-H., A. Bricaud, and A. Morel (1992), Light backscattering efficiency and related properties of some phytoplankters, Deep Sea Res., 39, $1835-1855$

Babin, M., A. Morel, V. Fournier-Sicre, F. Fell, and D. Stramski (2003), Light scattering properties of marine particles in coastal and open ocean waters as related to the particle mass concentration, Limnol. Oceanogr., $48,843-859$.

Baker, K. S., and R. C. Smith (1982), Bio-optical classification and model of natural waters, Limnol. Oceanogr., 27, 500-509.

Barnard, A. H., W. S. Pegau, and J. R. V. Zaneveld (1998), Global relationships of the inherent optical properties of the oceans, J. Geophys. Res., 103, 24955-24968, doi:10.1029/98JC01851.

Boss, E., W. S. Pegau, W. D. Gardner, J. R. V. Zaneveld, A. H. Barnard, M. S. Twardowski, G. C. Chang, and T. D. Dickey (2001), Spectral particulate attenuation and particle size distribution in the bottom boundary layer of a continentl shelf, J. Geophys. Res., 106, 9509-9516, doi:10.1029/2000JC900077.

Bricaud, A., and D. Stramski (1990), Spectral absorption coefficients of living phytoplankton and nonalgal biogenous matter: A comparison between the Peru upwelling area and Sargasso Sea, Limnol. Oceanogr., 35, $562-582$.

Bricaud, A., A. Morel, and L. Prieur (1981), Absorption by dissolved organic matter of the sea (yellow substance) in the UV and visible domains, Limnol. Oceanogr., 26, 43-53.

Bricaud, A., A. L. Bedhomme, and A. Morel (1988), Optical-properties of diverse phytoplanktonic species: Experimental results and theoretical interpretation, J. Plankton Res., 10(5), 851-873, doi:10.1093/plankt/ 10.5.851.

Bricaud, A., M. Babin, A. Morel, and H. Claustre (1995), Variability in the chlorophyll-specific absorption coefficients of natural phytoplankton: Analysis and parameterization, J. Geophys. Res., 100, 13321-13332, doi:10.1029/95JC00463.

Bricaud, A., A. Morel, M. Babin, K. Allali, and H. Claustre (1998), Variations of light absorption by suspended particles with chlorophyll a concentration in oceanic (case 1) waters: Analysis and implications for bio-optical models, J. Geophys. Res., 103, 31033-31044, doi:10.1029 98JC02712

Bricaud, A., H. Claustre, J. Ras, and K. Oubelkheir (2004), Natural variability of phytoplanktonic absorption in oceanic waters: Influence of size structure of algal populations, J. Geophys. Res., 109, C11010, doi:10.1029/2004JC002419.

Brown, C. A., Y. Huot, P. J. Werdell, B. Gentili, and H. Claustre (2008), The origin and global distribution of second order variability in satellite ocean color and its potential applications to algorithm development, Remote Sens. Environ., 112, doi:10.1016/j.RSE.2008.06.008.

Chavez, F. P., K. R. Buck, R. R. Bidigare, D. M. Karl, D. Hebel, M. Latasa, and L. Campbell (1995), On the chlorophyll a retention properties of glass-fiber GF/F filters, Limnol. Oceanogr., 40, 428-433.

Clark, D. K. (1981), Phytoplankton algorithms for the NIMBUS-7 CZCS, in Oceanography From Space, edited by J. F. R. Gower, pp. 227-238, Plenum, New York.

Garver, S. A., and D. A. Siegel (1997), Inherent optical property inversion of ocean color spectra and its biogeochemical interpretation: 1. Time series from the Sargasso Sea, J. Geophys. Res., 102, 18,607-18,625, doi:10.1029/96JC03243.

Gordon, H. R. (1989a), Can the Lambert-Beer law be applied to the diffuse attenuation coefficient of ocean water?, Limnol. Oceanogr., 34, 13891409 .

Gordon, H. R. (1989b), Dependence of the diffuse reflectance of natural waters on the sun angle, Limnol. Oceanogr., 34, 1484-1489.

Gordon, H. R., and A. Morel (1983), Remote Assessment of Ocean Color for Interpretation of Satellite Visible Imagery: A Review, 114 pp., Springer, New York.
Gordon, H. R., O. B. Brown, R. H. Evans, J. W. Brown, R. C. Smith, K. S. Baker, and D. K. Clark (1988), A semianalytic radiance model of ocean color, J. Geophys. Res., 93, 10,909-10,924, doi:10.1029/ JD093iD09p10909.

Hooker, S. B., C. R. McClain, J. K. Firestone, T. L. Westphal, E.-N. Yeh, and Y. Ge (1994), The SeaWiFS bio-optical archive and storage system (SeaBASS), part 1, NASA Tech. Memo., TM-104566, 20, 1-40.

Huot, Y., A. Morel, M. S. Twardowski, D. Stramski, and R. A. Reynolds (2008), Particle optical backscattering along a chlorophyll gradient in the upper layer of the eastern South Pacific Ocean, Biogeosciences, 5, 495507.

International Ocean Colour Coordinating Group (IOCCG) (2006), Remote sensing of inherent optical properties: Fundamentals, test of algorithms, and applications, edited by Z. P. Lee, Rep. 5, pp. 1-126, Dartmouth, Canada.

Kirk, J. T. O. (1994), Light and Photosynthesis in Aquatic Ecosystems, 507 pp., Cambridge Univ. Press, Cambridge, U.K.

Kishino, M., M. Takahashi, N. Okami, and S. Ichimura (1985), Estimation of the spectral absorption of phytoplankton in the sea, Bull. Mar. Sci., 37, 634-642.

Kopelevich, O. V. (1983), Small-parameter model of optical properties of sea water, in Ocean Optics, vol. 1, Physical Ocean Optics, edited by A. S. Monin, chap. 8, Nauka, Moscow (in Russian).

Loisel, H., and A. Morel (1998), Light scattering and chlorophyll concentration in case 1 waters: A reexamination, Limnol. Oceanogr., 43, 847-858.

Maritorena, S., and D. A. Siegel (2006), The GSM semi-analytical biooptical model, Rep. 5, pp. 81-86, Int. Ocean Colour Coordinating Group, Dartmouth, Canada.

Maritorena, S., D. A. Siegel, and A. Peterson (2002), Optimization of a semi-analytical ocean color model for global applications, Appl. Opt., 41, 2705-2714, doi:10.1364/AO.41.002705

Mobley, C. D. (1994), Light and Water: Radiative Transfer in Natural Waters, 592 pp., Academic, San Deigo, Calif.

Mobley, C. D., D. Stramski, W. P. Bissett, and E. Boss (2004), Optical modeling of ocean waters: Is the case 1-case 2 classification still useful?, Oceanography, 17, 61-67.

Morel, A. (1973), Diffusion de la lumière par les eaux de mer: Résultats expérimentaux et approche théorique, in Optics of the Sea, edited by NATO, AGARD Lectures Ser, vol. 61, pp. 3.1.1-3.1.76.

Morel, A. (1988), Optical modeling of the upper ocean in relationto its biogenous matter content, J. Geophys. Res., 93, 10,749-10,768, doi:10.1029/JC093iC09p10749.

Morel, A., and B. Gentili (2004), Radiation transport within oceanic (case 1) water, J. Geophys. Res., 109, C06008, doi:10.1029/2003JC002259.

Morel, A., and S. Maritorena (2001), Bio-optical properties of oceanic waters: A reappraisal, J. Geophys. Res., 106, 7163-7180, doi:10.1029/ 2000JC000319.

Morel, A., D. Antoine, and B. Gentili (2002), Bidirectional reflectance of oceanic waters: Accounting for Raman emission and varying particle scattering phase function, Appl. Opt., 41, 6289-6306, doi:10.1364/ AO.41.006289.

Morel, A., B. Gentili, M. Chami, and J. Ras (2006), Bio-optical properties of high chlorophyll case 1 waters, and of yellow substance-dominated case 2 waters, Deep Sea Res., Part I, 53, 1439-1459, doi:10.1016/ j.dsr.2006.07.007.

Morel, A., H. Claustre, D. Antoine, and B. Gentili (2007a), Natural variability of bio-optical properties in case 1 waters: Attenuation and reflectance within the visible and near-UV spectral domains as observed in South Pacific and Mediterranean waters, Biogeosciences, 4, 2147-2178.

Morel, A., B. Gentili, H. Claustre, M. Babin, A. Bricaud, J. Ras, and F. Tièche (2007b), Optical properties of the "clearest" waters, Limnol. Oceanogr., $52,217-229$.

Morel, A., Y. Huot, B. Gentili, P. J. Werdell, S. B. Hooker, and B. A. Franz $(2007 \mathrm{c})$, Examining the consistency of products derived from various ocean color sensors in open ocean (case 1) waters in the perspective of a multi-sensor approach, Remote Sens. Environ., 111, 69-88, doi:10.1016/j.rse.2007.03.012.

Mueller, J. L., and G. S. Fargion (2002), Ocean optics protocols for satellite ocean color sensor validation, NASA Tech. Memo., TM-210004, 308 pp.

Nelson, N. B., D. A. Siegel, and A. F. Michaels (1998), Seasonal dynamics of colored dissolved material in the Sargasso Sea, Deep Sea Res. Part I, 45, 931-957, doi:10.1016/S0967-0637(97)00106-4.

O'Reilly, J. E., S. Maritorena, B. G. Mitchell, D. A. Siegel, K. L. Carder, A. Garver, M. Kahru, and C. McClain (1998), Ocean color algorithms for SeaWiFS, J. Geophys. Res., 103, 24,937-24,953, doi:10.1029/ 98JC02160.

O'Reilly, J. E., et al. (2000), Ocean color chlorophyll a algorithms for SeaWiFS, OC2, and OC4: Version 4, in SeaWiFS Postlaunch Calibration and Validation Analyses, Part 3, NASA Tech. Memo., TM-206892, vol. 11, pp. $9-23$. 
Pope, R. M., and E. S. Fry (1997), Absorption spectrum (380-700 nm) of pure water, II. Integrating cavity measurements, Appl. Optics, 36, 87108723.

Preisendorfer, R. W. (1961), Application of radiative transfer theory to light measurement in the sea, Int. Union Geod. Geophys. Monogr., 10, 11-30

Prieur, L., and S. Sathyendranath (1981), An optical classification of coastal and oceanic waters based on the specific spectral absorption of phytoplankton pigments, dissolved organic matter and other particulate materials, Limnol. Oceanogr., 26, 671-689.

Roesler, C. S., M. J. Perry, and K. L. Carder (1989), Modeling in situ phytoplankton absorption from total absorption spectra in productive inland waters, Limnol. Oceanogr., 34, 1510-1523.

Shifrin, K. S. (1983), Physical Optics of Ocean Water, 285 pp., Am. Inst. of Phys, New York.

Siegel, D. A., S. Maritorena, N. B. Nelson, D. A. Hansell, and M. LorenziKayser (2002), Global ocean distribution and dynamics of colored dissolved and detrital organic material, J. Geophys. Res., 107(C12), 3228 , doi:10.1029/2001JC000965.

Siegel, D. A., S. Maritorena, N. B. Nelson, M. J. Behrenfeld, and C. R. McClain (2005a), Colored dissolved organic matter and its influence on the satellite-based characterization of the ocean biosphere, Geophys. Res. Lett., 32, L20605, doi:10.1029/2005GL024310.

Siegel, D. A., S. Maritorena, N. B. Nelson, and M. J. Behrenfeld (2005b), Independence and interdependencies among global ocean color properties: Reassessing the bio-optical assumption, J. Geophys. Res., 110, C07011, doi:10.1029/2004JC002527.

Smith, R. C., and K. S. Baker (1978), The bio-optical state of ocean waters and remote sensing, Limnol. Oceanogr., 23, 247-259.

Stramski, D., A. Bricaud, and A. Morel (2001), Modeling the inherent optical properties of the ocean based on the detailed composition of the planktonic community, Appl. Opt., 40, 2929-2945, doi:10.1364/ AO.40.002929.

Twardowski, M. S., E. Boss, J. B. Macdonald, W. S. Pegau, A. Barnard, and J. R. V. Zaneveld (2001), A model for estimating bulk refractive index from the optical backscattering ratio and the implications for understanding particle composition in case I and case II waters, J. Geophys. Res., 106, 14,129-14,142, doi:10.1029/2000JC000404.

Twardowski, M. S., E. Boss, J. M. Sullivan, and P. L. Donaghay (2004), Modeling the spectral shape of absorption by chromophoric dissolved organic matter, Mar. Chem., 89, 48-69, doi:10.1016/j.marchem.2004. 02.008 .

Ulloa, O., S. Sathyendranath, and T. Platt (1994), Effect of particle-size distribution on the backscattering ratio in seawater, Appl. Opt., 33, 70707077 .

Voss, K. J. (1992), A spectral model of the beam attenuation coefficient in the ocean and coastal areas, Limnol. Oceanogr., 37, 501-509.

Werdell, P. J., and S. W. Bailey (2005), An improved in-situ bio-optical data set for ocean color algorithm development and satellite data product validation, Remote Sens. Environ., 98, 122-140, doi:10.1016/ j.rse.2005.07.001

Werdell, P. J., S. W. Bailey, B. A. Franz, A. Morel, and C. R. McClain (2007), On-orbit vicarious calibration of ocean color sensors using an ocean surface reflectance model, Appl. Opt., 46, 5649-5666, doi:10.1364/AO.46.005649

A. Morel, Laboratoire d'Océanographie de Villefranche, Université Pierre et Marie Curie et Centre National de la Recherche Scientifique, F-06238 Villefranche-sur-mer, France. (morel@obs-vlfr.fr) 